\title{
A hierarchical Bayesian model for embedding larval drift and habitat models in integrated life cycles for exploited fish
}

\author{
S. Rochette,${ }^{1,2,4}$ O. Le Pape, ${ }^{2}$ J. Vigneau, ${ }^{3}$ And E. Rivot ${ }^{2}$ \\ ${ }^{1}$ Ifremer, Département Dynamiques de l'Environnement Côtier, Laboratoire Applications Géomatiques, CS 10070, \\ 29280 Plouzané, France \\ ${ }^{2}$ Agrocampus Ouest, UMR 985, Ecologie et Santé des Ecosystèmes, Laboratoire d'Ecologie Halieutique, \\ 65 Rue de St Brieuc, CS 84215, 35042 Rennes, France \\ ${ }^{3}$ Ifremer, Laboratoire Ressources Halieutiques, 14520 Port-en-Bessin, France
}

\begin{abstract}
This paper proposes a hierarchical Bayesian framework for modeling the life cycle of marine exploited fish with a spatial perspective. The application was developed for a nursery-dependent fish species, the common sole (Solea solea), on the Eastern Channel population (Western Europe). The approach combined processes of different natures and various sources of observations within an integrated framework for life-cycle modeling: (1) outputs of an individual-based model for larval drift and survival that provided yearly estimates of the dispersion and mortality of eggs and larvae, from spawning grounds to settlement in several coastal nurseries; (2) a habitat suitability model, based on juvenile trawl surveys coupled with a geographic information system, to estimate juvenile densities and surface areas of suitable juvenile habitat in each nursery sector; (3) a statistical catch-at-age model for the estimation of the numbers-at-age and the fishing mortality on subadults and adults. The approach provided estimates of hidden variables and parameters of key biological significance. A simulation approach provided insight to the robustness of the approach when only weak data are available. Estimates of spawning biomass, fishing mortality, and recruitment were close to the estimations derived from stock-assessment working groups. In addition, the model quantified mortality along the life cycle, and estimated site-specific density-dependent mortalities between settled larvae and age-0 juveniles in each nursery ground. This provided a better understanding of the productivity and the specific contribution of each nursery ground toward recruitment and population renewal. Perspectives include further development of the modeling framework on the common sole and applications to other fish species to disentangle the effects of multiple interacting stress factors (e.g., estuarine and coastal nursery habitat degradation, fishing pressure) on population renewal and to develop risk analysis in the context of marine spatial planning for sustainable management of fish resources.
\end{abstract}

Key words: Eastern Channel (Western Europe); habitat suitability model; hierarchical Bayesian model; hydrodynamic models; integrated model; larval drift; life cycle; nursery; recruitment; sole; Solea solea; spatially structured.

\section{INTRODUCTION}

To better manage fisheries and other exploited populations, there is a growing appreciation that population models must account for spatial variability in processes affecting key life history (Ruiz et al. 2009, Blackwood et al. 2011, Maunder and Deriso 2011, Petitgas et al. 2013). A fair understanding of the mechanisms underlying fish spatial distribution throughout their life cycle is needed for an accurate representation of the processes regulating populations (Carson et al. 2011, van de Wolfshaar et al. 2011, Ying et al. 2011). It is also a prerequisite for the assessment of spatialmanagement measures such as marine protected areas or

Manuscript received 28 February 2012; revised 14 March 2013; accepted 21 March 2013. Corresponding Editor: S. B. Baines.

${ }^{4}$ E-mail: sebastien.rochette@ifremer.fr essential fish habitat protection (Pelletier and Mahévas 2005, Grüss et al. 2011, Hinrichsen et al. 2011, White and Costello 2011). Still, modeling fish life cycle in a spatial perspective remains a difficult challenge. It requires characterizing the ecological processes underlying the spatio-temporal variability of different life stages, and integrating multiple interacting anthropogenic pressures that affect different stages of the life cycle.

The difficulty in understanding how recruitment processes vary over space and time has particularly hampered model development (Houde 2008). The life cycles of most of the marine fish species are characterized by high and often unpredictable mortality in their pelagic early life stages (May 1974, Chambers and Trippel 1997, Minto et al. 2008). The mortality of early life stages and recruitment success is intimately related to factors controlling their dispersion and their trans- 


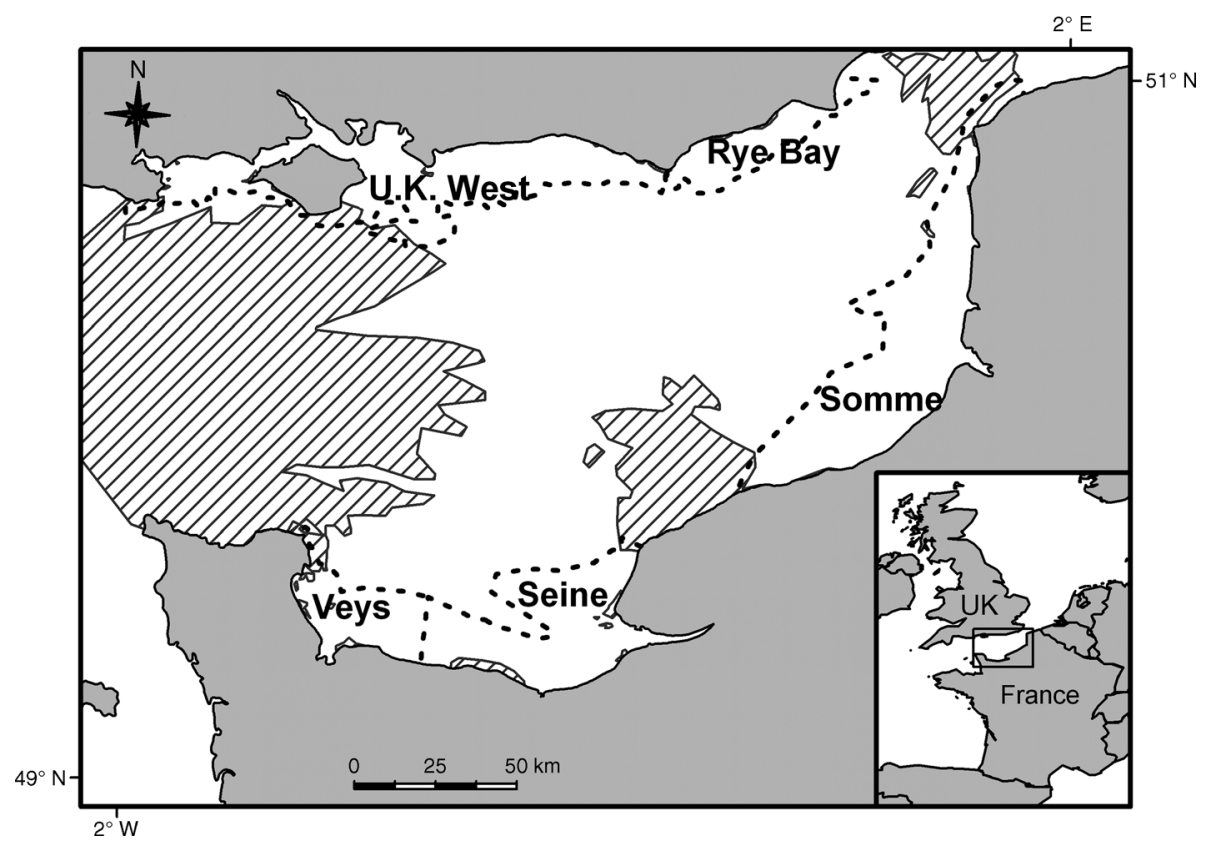

FIG. 1. The five coastal nursery sectors for the common sole (Solea solea) identified in the Eastern Channel (fine dotted lines) of Western Europe. The hatched area indicates pebbles and rocks.

port to suitable nursery habitats (Gallego et al. 2012). Recently, physical and physiological models have been coupled to simulate transport and mortality of early life stages, and provide insight into the connectivity and variability of larval supply and juvenile distribution (Miller 2007, Huret et al. 2010, Fässler et al. 2011, Gallego et al. 2012). Embedding models for drift and survival of early life stages within life cycles, including growth and survival in essential nursery habitats (van de Wolfshaar et al. 2011), requires the combination of different modeling approaches, which remains challenging (Planque et al. 2011).

We propose a general template for merging different sources of knowledge and data to build integrated lifecycle models for marine fish species that include the larval drift process, the contribution of several nurseries to recruitment, and natural and fishing mortalities. Hierarchical Bayesian models (HBMs) are proposed as a framework for such a synthesis (Cressie et al. 2009). HBMs coupled with Markov chain-Monte Carlo methods (Brooks 2003, Lunn et al. 2009, Newmann et al. 2009) allow embedding complex demographic models within statistical models for various sources of data, often noisy and incomplete, and provide inferences together with a fair appraisal of the uncertainty around parameter estimates and predictions (Thomas et al. 2005, Buckland et al. 2007, Parent and Rivot 2012). Widely applied for age-structured (Millar and Meyer 2000, Lewy and Nielsen 2003, Fernandez et al. 2010, Simmonds et al. 2010) or stage-structured (Rivot et al. 2004, Ruiz et al. 2009, Swain et al. 2009) fish population dynamics, HBMs may increase biological realism of fisheries stock assessment (Kuparinen et al. 2012). A few papers have recently used hierarchical models for spatially structured demographic models of exploited marine fish populations (Cunningham et al. 2007, Drouineau et al. 2010), but to date no complete lifecycle model for marine fish species explicitly including larval drift processes, and quantifying the contribution of several habitats to the recruitment has been proposed and fitted in the Bayesian setting.

The aim of the present paper is to lay the foundations for such an integrated life cycle model through an application on the common sole (Solea solea) population in the Eastern Channel (EC, Western Europe; Fig. 1). The common sole is a widely distributed flatfish species, with a high commercial interest (Gibson 2005). The common sole population in the EC is an ideal candidate to illustrate our generic approach. Juveniles of common sole spend the first two years of their life in coastal nurseries before migrating to deeper areas, where they reproduce and are harvested (Riou et al. 2001). The seasonal and spatial distribution of spawning can be estimated from egg surveys (van der Land 1991). Individual-based models coupled with hydrodynamical models have been developed to provide insight on eggs and larvae survival and on transport from spawning grounds to suitable nursery habitats (Rochette et al. 2012). After metamorphosis and settlement on nurseries, density-dependent and densisty-independent mechanisms regulate the number of juveniles (Iles and Beverton 2000) on restricted coastal and estuarine nursery areas (Riou et al. 2001). Habitat-suitability models have been developed to assess and map the 


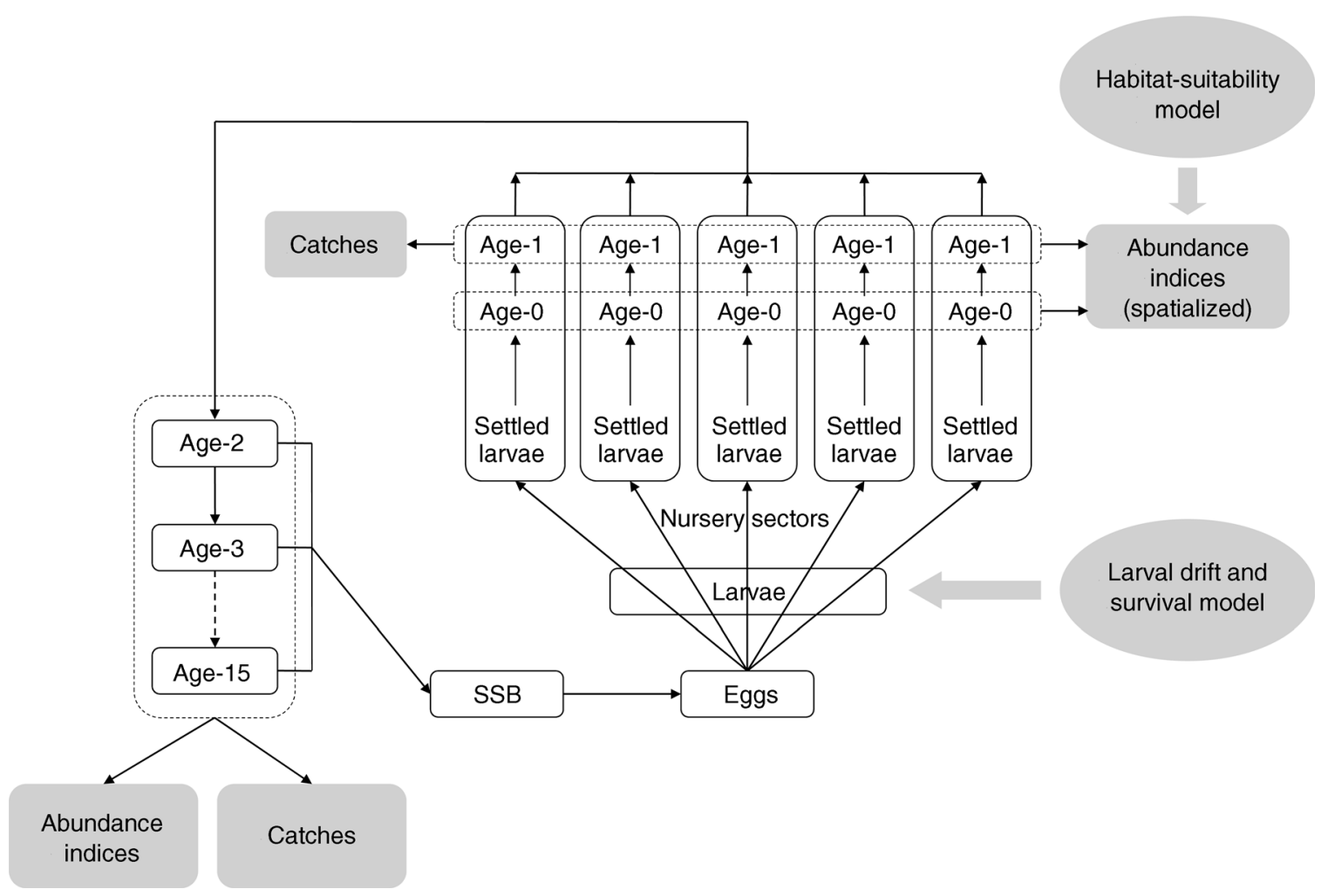

FIG. 2. Schematic diagram of the hierarchical life-cycle model. White boxes are the hidden population-dynamics model; gray boxes are the observation processes; ellipses and large arrows are inputs from other models; SSB is spawning stock biomass.

carrying capacity of sole nurseries for the EC population (Rochette et al. 2010). Statistical catch-at-age models, based on fishery-dependent data and scientific survey, are routinely used in stock-assessment procedures to quantify abundance and the effect of fishing mortality on subadults and adults (ICES 2009).

In this paper we build an HBM that merges data and models of different nature into an integrated framework that provides a fair representation of the mechanisms underlying (1) the larval drift, mostly driven by environmental factors, (2) the density-dependent postsettlement mortality of juveniles depending upon the quality of nursery habitats, and (3) the population dynamics of subadults and adults under commercial exploitation. The approach was primarily designed to account for the multiple factors that affect populations at different life stages, including fishing mortality, but also the effect of environmental conditions on larval drift and survival, and the effect of anthropogenic pressures affecting nursery habitats. Results from this model would also provide a better understanding of the productivity and specific contribution of different nursery grounds to the population renewal. These are prerequisites for a comprehensive understanding of the life cycle and for the assessment of spatially explicit management measures such as the conservation and restoration of coastal and estuarine nursery habitats (Beck et al. 2001).

\section{Material and Methods}

\section{Outlines of the modeling approach}

The life-cycle model (Fig. 2) was proposed in a statespace formulation that can accommodate uncertainties in the way ecological processes operate (process stochasticity) and are observed (observation error). The model is structured by age and life stage and includes the following key features: (1) The spatial structure of the population is represented for all stages ranging from pelagic eggs to juveniles at age 2. Eggs and larvae are transported from spawning areas and settle on different coastal nursery sectors. The dispersion and the survival rates from eggs to settled larvae in nurseries were derived from a biophysical model (Rochette et al. 2012) that incorporates interactions between hydrodynamical conditions and key biological features of early life stages. After settlement on coastal and estuarine sectors of the Eastern Channel (Western Europe), juveniles suffer site-specific mortality. The spatial stratification of juveniles was simplified from Rochette et al. (2010) to account for five different nursery sectors with contrasting levels of production: U.K. West, Rye Bay, Somme, Seine, and Veys (Fig. 1; Table 1), on which time series of abundance indices are available for age- 0 and age- 1 juveniles. (2) Young fish were assumed to leave nurseries at age 2 to contribute to a single homogeneous population in the Eastern Channel (EC), 
TABLE 1. Characteristics of the five common sole (Solea solea) nurseries in the Eastern Channel (Western Europe).

\begin{tabular}{lcc}
\hline \hline Nursery & $\begin{array}{c}\text { Surface area } \\
\left(\mathrm{km}^{2}\right)\end{array}$ & $\begin{array}{c}\text { Number of years with } \\
\text { available abundance indices } \\
\text { (ages 0, 1) over the 1982-2008 } \\
\text { time series }\end{array}$ \\
\hline 1) U.K. West & 2266 & 18 \\
2) Rye Bay & 729 & 25 \\
3) Somme & 2441 & 21 \\
4) Seine & 1551 & 8 \\
5) Veys & 706 & 0
\end{tabular}

with 14 age classes between age 2 and age 15 . Commercial fishery occurs for fish at age 1 in coastal sectors, and for fish between ages 2 and 15 in the open sea (ICES 2009). A statistical catch-at-age model was used to incorporate time series of commercial catches and scientific surveys to provide information about the number of individuals for each age class in the population. Fish from ages 3 to 15 contribute to the spawning biomass.

To test the model's ability to estimate all states variables and parameters, it was applied to simulated data before being fitted to the data available for the EC. Simulations were tailored to mimic the application to the sole population in the EC. They were designed to test the performance of the estimation method and especially its robustness to missing data in the time series of both larval drift survival rates and juvenile abundance indices in nursery sectors.

Bayesian inferences rely on the general theory of state-space models (Buckland et al. 2007, Parent and Rivot 2012). The full joint posterior distribution of all unknown parameters and states variables is decomposed into the joint prior on all parameters, the prior on hidden state variables given the parameters, and the full likelihood, which is the distribution of the data given the state variables and the parameters.

To keep the presentation clear, we first detail the general equations of the demographic that provide the joint prior for the state variables given the parameters. Then, stochastic observation equations that form the likelihood are provided. The prior distributions on parameters are then justified, together with details about the data available in the EC case study. The simulation plan is detailed in Material and methods: Testing the performance of the estimation methods .... .

\section{Hidden stochastic demographic process}

The model is written in a state-space formulation. The numbers of fish per age or stage are hidden state variables to be estimated. The number of juveniles of the first two age classes $(a=0$ and $a=1)$ at the beginning of each year $y$ in each of the five nursery sectors $i$ (Table 1; Fig. 1) are denoted $N_{a, y, i}$. Fish of ages $a=2, \ldots, 15$ belong to one single population with homogeneous biological and fishery-related parameters, with number denoted $N_{a, y}$.

Subadults and adults. - Cohort dynamics for ages 2-15 followed the standard equation:

$$
N_{a+1, y+1}=N_{a, y} \times e^{-Z_{a, y}} \times e^{\varepsilon_{a, y}}
$$

where $Z_{a, y}$ is the total mortality rate at age $a$ in year $y$, defined as the sum of natural mortality $M_{a}$, considered constant across years and fishing mortality $F_{a, y}$, and $\varepsilon_{a, y}$ is a Normal environmental noise with variance $\sigma_{p}^{2}$. For age 2 and more, $M_{a}$ was considered known and scaled so that only a negligible number of fish survive after age 15 (Table 2). All fish were assumed to die from natural mortality after age 15 . Between-year variability of $F_{a, y}$ was captured through a random hierarchical structure for $F_{a, y}$ modeled as a random variable following a Gamma distribution with expected mean $\mu_{F a, y}$ and coefficient of variation $\mathrm{CV}_{F}$. A separable model was specified for $\mu_{F a, y}$ :

$$
\mu_{F a, y}=S_{a} \times E_{y}
$$

with $S_{a}$ an age-specific selectivity, and $E_{y}$ a year-specific fishing effort (Quinn and Deriso 1999). Selectivity $S_{a}$ was modeled by a logistic function (with $S_{a=15}=1$ ) as parameterized by Mesnil and Shepherd (1990) (Table 3). Fishing effort $E_{y}$ was considered as randomly fluctuating between years following a Gamma distribution with expected mean $\mu_{E}$ and coefficient of variation $\mathrm{CV}_{E}$.

Fish between ages 3 and 15 take part in reproduction (Fig. 2). The total amount of eggs for each year $\left(\omega_{y}\right)$ was calculated from the spawning stock biomass by combining abundance at age in Eq. 1 with equations of female egg production used in Rochette et al. (2012).

Eggs and larvae.-The transition from eggs (spawned around early spring) to settled larvae in each nursery relies on the outputs of the larval drift and survival model developed by Rochette et al. (2012). The annual number of settled larvae that are distributed among the

TABLE 2. Fixed parameters used in the population-dynamics model.

\begin{tabular}{llll}
\hline \hline Eq. & Parameters & \multicolumn{1}{c}{ Value } & \multicolumn{1}{c}{ Source } \\
\hline 1 & $M_{2}$ to $M_{10}$ & $=0.1 \mathrm{yr}^{-1}$ & ICES (2009) (based on expertize) \\
& $M_{11}$ to $M_{15}$ & increases linearly from 0.1 to $0.5 \mathrm{yr}^{-1}$ & see Material and methods \\
9 & $M_{0}$ & $=1.5 \mathrm{yr}^{-1}$ applied only from September to December & $\begin{array}{l}\text { derived from Dorel et al. (1989) } \\
\text { derived from Dorel et al. (1989) } \\
10\end{array} M_{1}$ \\
11 & $\sigma_{C}^{2}$ & 0.02 & J. Vigneau, personal communication \\
$1,9-10$ & $\sigma_{p}^{2}$ & 0.01 & this paper \\
\hline
\end{tabular}

Note: $M_{i}$ is mortality per age class (years 0 through 15 ); $\sigma_{C}^{2}$ is the variance of the log-normal error on observation of catches; $\sigma_{p}^{2}$ is the variance of the Gaussian environmental noise on the mortality between age classes. 
TABLE 3. Prior distributions.

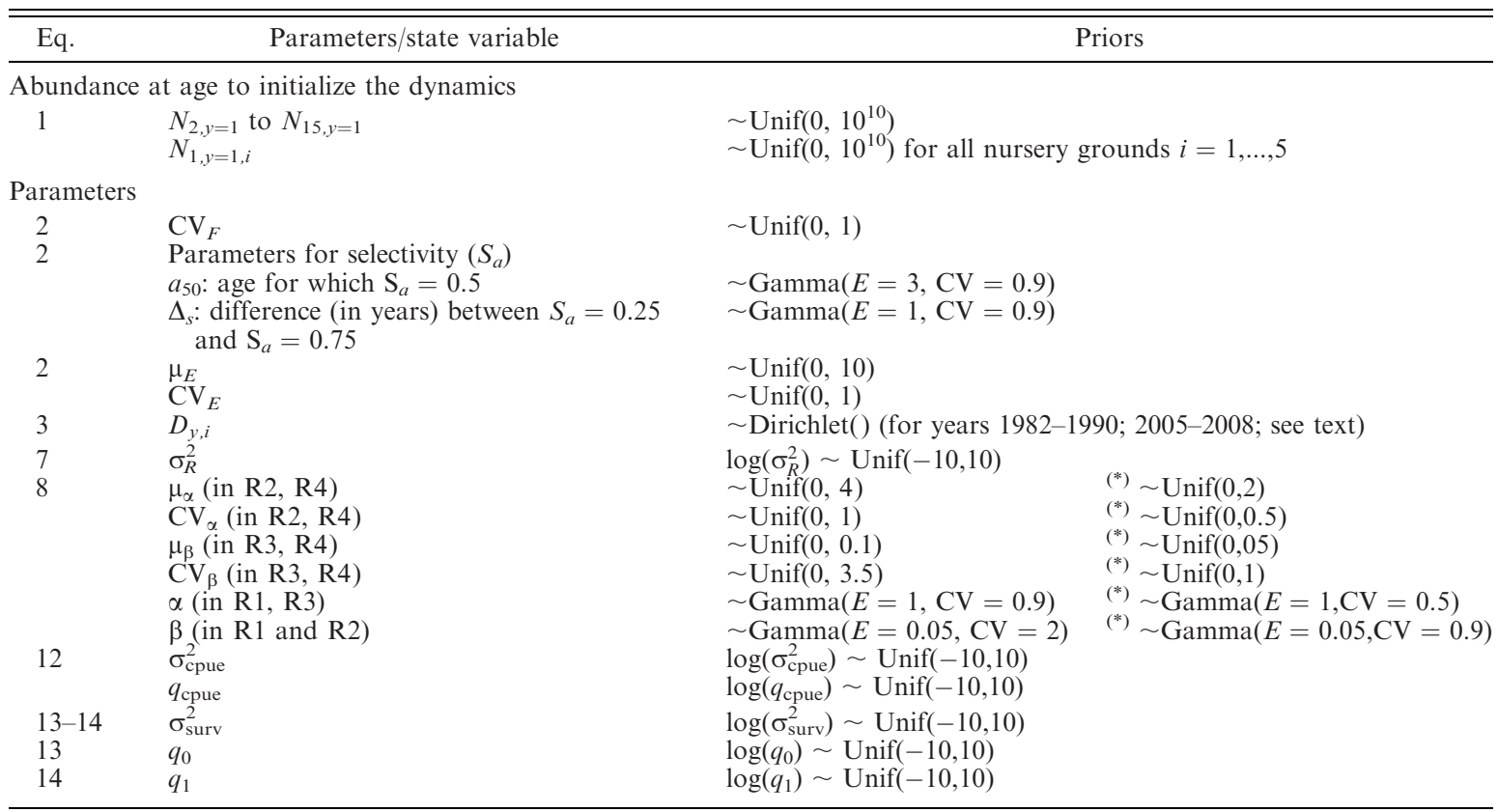

Notes: Superscript "(*)" indicates the priors used in the sensitivity analysis. Definitions of the parameters/state variables: $N_{a, y}$ is the number of individuals at age $a$ and year $y ; \mathrm{CV}_{F}$ is the coefficient of variation on the fishing mortality; $S_{a}$ is selectivity at age of the fishery; $\mu_{E}$ and $\mathrm{CV}_{E}$ are the mean and coefficient of variation of the prior distribution of the fishing effort; $D_{y, i}$ is the drift and survival rate of larvae distributed in the nursery $i$ for the year $y$ for one egg spawned; $\sigma_{R}^{2}$ is the variance (in log scale) of the lognormal mortality process between larvae and age- 0 juveniles; $\alpha$ and $\beta$ are the site-specific density-dependent and densityindependent mortality rates, respectively, between larvae and age- 0 juveniles, $\mu$ and $\mathrm{CV}$ being the mean and coefficient of variations of Gamma distribution of priors for $\alpha$ and $\beta$, which are either nursery-specific or common depending on scenarios of the model; $\sigma_{\text {cpue }}^{2}$ is the variance $\left(\log\right.$ scale) of the error of observation of abundance indices for ages $2-15 ; q_{\text {cpue }}$ is the catchability of the scientific fishery survey; $\sigma_{\text {surv }}^{2}$ is the variance (in log scale) of the error of observation of juvenile abundance indices; $q_{0}$ and $q_{1}$ are the age- 0 and age- 1 catchability of the scientific fishery survey. CPUE is catch per unit effort.

nurseries, denoted as $L_{y, i}$, was modelled as the product between the total number of eggs spawned $\omega_{y}$ and the drift survival rates $D_{y, i}$ derived from the larval transport model (see Fitting the model to available data in the Eastern Channel, below):

$$
L_{y, i}=\omega_{y} \times D_{y, i}
$$

Age 0 and age 1 juveniles on nursery grounds.According to the concentration hypothesis (Iles and Beverton 2000), the mortality in each nursery ground between larval settlement (about late Spring, in June) and the end of age- 0 juveniles growth period in September (matching with the survey period) was considered to be density dependent. The mortality was modeled through a Beverton and Holt ( $\mathrm{B}$ and $\mathrm{H}$ )-type relationship using parameters related to the instantaneous mortality rate (modified from Quinn and Deriso 1999):

$$
\frac{1}{n_{t, i}^{*}} \times \frac{d n_{t, i}^{*}}{d t}=-\alpha_{i}-\beta_{i} \times n_{t, i}^{*}
$$

where $n_{t, i}^{*}=n_{t, i} / A_{i}$ is the density at time $t$ in the nursery $i$ ( $A_{i}$ is the surface area of the nursery sector $i$; Table 1 ), and $\alpha_{i}$ and $\beta_{i}$ are the site-specific density-independent and density-dependent mortality rates, respectively. Starting from the number of larvae per unit of surface area $L_{y, i}^{*}$, the instantaneous mortality in Eq. 4 is integrated out on a duration equal to $1 / 4$ of a year (i.e., three months between June and early September) to produce the number of age- 0 juveniles in September per unit of surface area:

$$
N_{0, y, i}^{*}=\frac{\psi_{i} \times L_{y, i}^{*}}{1+\frac{\psi_{i}}{K_{i}} \times L_{y, i}^{*}}
$$

with site-specific parameters $\psi_{i}$ (maximum survival rate) and $K_{i}$ (carrying capacity per unit of surface area) defined as

$$
\left\{\begin{aligned}
\psi_{i} & =e^{-(1 / 4) \alpha_{i}} \\
K_{i} & =\frac{\alpha_{i}}{\beta_{i}} \times \frac{1}{e^{-(1 / 4) \alpha_{i}}-1} .
\end{aligned}\right.
$$

Interannual random variations around the expected mortality process were captured by lognormal process errors, with recruitment variance $\sigma_{R}^{2}$ (in $\log$ scale) assumed as being identical in the five nurseries. A correction was added (Laurent 1963) to ensure the expected mean of the number of age- 0 juveniles is 
$N_{0, y, i}^{*} \times A_{i}$ :

$$
\log \left(N_{0, y, i}\right) \sim \operatorname{Normal}\left(\log \left[N_{0, y, i}^{*} \times A_{i}-0.5 \times \sigma_{R}^{2}\right], \sigma_{R}^{2}\right) .
$$

Four competing recruitment hypotheses (R1-R4) regarding the between-nurseries variability of the density-dependent and density-independent mortality rates (Eq. 4) were tested:

R1) $\alpha$ and $\beta$ are common to all nurseries;

R2) the $\alpha_{i}$ 's are nursery-specific, and $\beta$ is common to all nurseries;

R3) the $\beta_{i}$ 's are nursery-specific, and $\alpha$ is common to all nurseries; and

R4) the $\alpha_{i}$ 's and the $\beta_{i}$ 's are nursery-specific.

Because only poor information is available to estimate site-specific parameters, exchangeable hierarchical structures (Gelman et al. 2004) were used to model the between-nursery variability of parameters $\alpha$ and $\beta$, allowing for "borrowing strength" between nursery sectors (Rivot and Prévost 2002, McAllister et al. 2004). In the less parsimonious hypothesis $\mathrm{R} 4$, both $\alpha_{i}$ 's and $\beta_{i}$ 's were a priori distributed as independent Gamma distributions with unknown means $\left(\mu_{\alpha}, \mu_{\beta}\right)$ and coefficients of variation $\left(\mathrm{CV}_{\alpha}, \mathrm{CV}_{\beta}\right)$ :

$$
\left\{\begin{array}{l}
\alpha_{i} \sim \operatorname{Gamma}\left(\mu_{\alpha}, \mathrm{CV}_{\alpha}\right) \\
\beta_{i} \sim \operatorname{Gamma}\left(\mu_{\beta}, \mathrm{CV}_{\beta}\right) .
\end{array}\right.
$$

Parameters common to all nurseries (for instance $\beta$ in hypothesis R2) were a priori Gamma distributed with fixed mean and CV (Table 3).

A four-month natural mortality (from September to December) with rate $M_{0}$ (considered constant between years and between sectors) was finally applied to age- 0 juveniles to produce the number of age- 1 juveniles in the following January in each nursery:

$$
N_{1, y+1, i}=N_{0, y, i} \times e^{-(1 / 3) M_{0}} \times e^{\varepsilon_{0, y, i}}
$$

where $\varepsilon_{0, y, i}$ is a Normal environmental noise with variance $\sigma_{p}^{2}$.

Age-1 juveniles spend one year in nursery grounds where they suffer a total mortality $Z_{1, y}=M_{1}+F_{1, y}$ assumed independent from the site, with fixed rate $M_{1}$. The pooled amount of age- 2 juveniles present next January was summed from the production of the five nurseries:

$$
N_{2, y+1}=\left(\sum_{i=1}^{i=5} N_{1, y, i}\right) \times e^{-Z_{1, y}} \times e^{\varepsilon_{2, y}} .
$$

\section{Stochastic observation equations}

The observations are from three sources (Fig. 2): (1) Time series of commercial catches for ages 1-15 and of (2) abundance indices for ages 2-15, available at the EC population scale, and (3) time series of abundance indices for age- 0 and age-1 juveniles, available for each nursery sector.

Catches-at-age $H_{a, y}$ for pooled age- 1 juveniles and for ages $2-15$ (considered as a hidden state variable in the model) were calculated with the standard Baranov equation (Quinn and Deriso 1999), and recorded catches $C_{a, y}$ were considered to be observed from $H_{a, y}$ with independent lognormal sampling errors with variance $\sigma_{C}^{2}:$

$$
\left\{\begin{array}{l}
H_{a, y}=\frac{F_{a, y}}{Z_{a, y}} \times N_{a, y} \times\left(1-e^{-Z_{a, y}}\right) \\
\log \left(C_{a, y}\right) \sim \operatorname{Normal}\left(\log \left[H_{a, y}\right]-0.5 \times \sigma_{C}^{2}, \sigma_{C}^{2}\right) .
\end{array}\right.
$$

Abundance indices for ages 2-15 (catch per unit effort, cpue), denoted $I_{a, y}$, were considered to be observed with independent lognormal errors with variance $\sigma_{\text {cpue }}^{2}$ :

$$
\begin{array}{r}
\log \left(I_{a, y}\right) \sim \operatorname{Normal}\left(\log \left[q_{\text {cpue }} \times S_{a} \times N_{a, y}\right]\right. \\
\left.-0.5 \times \sigma_{\text {cpue }}^{2}, \sigma_{\text {cpue }}^{2}\right)
\end{array}
$$

with $q_{\text {cpue }}$ the catchability and $S_{a}$ the age-specific selectivity of the fishery.

Abundance indices for both age- 0 and age- 1 juveniles, available in each nursery sector and denoted as $I_{0, y, i}$ and $I_{1, y, i}$, were assumed to be observed with age-specific catchability $q_{0}$ and $q_{1}$ (supposed constant between years and common to all nurseries) and independent lognormal errors with variance $\sigma_{\text {surv }}^{2}$ supposed common to age classes and to all nurseries:

$$
\left\{\begin{array}{c}
\log \left(I_{0, y, i}\right) \sim \operatorname{Normal}\left(\log \left[q_{0} \times N_{0, y, i}\right]-0.5 \times \sigma_{\text {surv }}^{2}, \sigma_{\text {surv }}^{2}\right) \\
\log \left(I_{1, y, i}\right) \sim \operatorname{Normal}\left(\log \left[q_{1} \times e^{-2 / 3 \times Z_{1, y}} \times N_{1, y, i}\right]\right. \\
\left.-0.5 \times \sigma_{\text {surv }}^{2}, \sigma_{\text {surv }}^{2}\right) .
\end{array}\right.
$$

The abundance of age- 1 juveniles $N_{1, y, i}$ in Eq. (13) was corrected to account for the mortality between the time when the abundance is considered in the model (i.e., in January) and the survey in September.

\section{Fitting the model to available data in the Eastern Channel}

Catch and abundance indices.-The model was fitted to available time series of catch and abundance indices. The time series is from 1982 to 2008 but includes missing data. Catches-at-age (in Eq. 11) were landings-at-age reported by the stock assessment working group (ICES 2009). As the last available age class in catch data was a $10+$ group, Eq. 11 was rewritten to consider the catches in the age- $10+$ group as a lognormal distribution with an expected mean equal to the sum of non-observed catches from ages 11-15. Abundance indices for ages 2-15 (in Eq. 12) were the 1986-2008 time series of CPUE calculated from the United Kingdom bottom-trawl fishery, considered as the most self-consistent time series for these ages (ICES 2009). 
Abundance indices of age- 0 and age- 1 juveniles in each nursery sector (Eq. 13) were derived from a habitat-suitability model modified from Rochette et al. (2010). The authors built a zero-inflated generalized linear model to analyze an extensive database of scientific beam-trawl surveys for sole juveniles on coastal and estuarine nursery grounds in the EC, with regards to the bathymetry and the sediment structure. This habitatsuitability model was modified by introducing sitespecific between-year variability and provided time series of abundance indices for each of the five nursery grounds.

Many data were missing in the time series of abundance indices of age- 0 and age- 1 juveniles in nursery grounds (47\% missing data; Table 1) but also for abundance indices of ages 2-15 (15\% missing data). Missing data were considered as Missing at Random, their posterior distribution being estimated as with any other unknown variable in the model (see Gelman et al. [2004] for theoretical considerations and Rivot et al. [2008] for an application).

Egg to larvae drift and survival rates.-The drift and survival rates $\left(D_{y, i}\right.$ in Eq. 3) were based on the hydrodynamical model of Rochette et al. (2012). Unfortunately, this provides results for only 14 years (1991-2004) out of the 1982-2008 period for which catches and abundance indices are available. When available, the $D_{y, i}$ 's were set equal to the outputs of Rochette et al. (2012). For years 1982-1990 and 20052008 , the $D_{y, i}$ 's were drawn in informative Dirichlet prior distributions (Gelman et al. 2004) derived from the available time series of $D_{y, i}$ 's from Rochette et al. (2012). For each year $y$, the Dirichlet defines a joint prior distribution for six coefficients that sum to 1 , the first one being the total mortality from eggs to settled larvae, and the five others being the $D_{y, i}$ 's. Because outputs of Rochette et al. (2012) showed two different regimes of larval supply in the 1992-2004 period, with a shift in 1997-1998 (illustrated later in Fig. 5), three alternative scenarios $D_{1}, D_{2}$, and $D_{3}$ were tested: the $D_{y, i}$ 's for years 1982-1990 and 2005-2008 were drawn in independent informative priors that reproduce the average regime of the whole period with information on larval drift from Rochette et al. (2012), i.e., 1991-2004 $\left(D_{1}\right)$, of the first seven years 1991-1997 $\left(D_{2}\right)$, or of the last seven years 1998-2004 $\left(D_{3}\right)$.

Fixed parameters.-Natural mortality rates of juveniles, $M_{0}$ and $M_{1}$ were fixed to values found in the literature (Table 2), and $M_{a}$ for ages $2-15$ to values similar to the ones used by the stock-assessment working group (ICES 2009). The variance of environmental noise $\sigma_{p}^{2}$ (that can be interpreted as Normal environmental variance of natural mortality rates) was arbitrarily fixed to 0.01 . This provides the demographic transition to be stochastic, while limiting identifiability issues with environmental variability of the fishing mortality rate $F_{a, y}$. The variance of the sampling error for catches $\left(\sigma_{C}^{2}\right)$ was fixed from available expertise from the stock- assessment working group (ICES 2009, J. Vigneau, personal communication) such that $\mathrm{CV}$ in catches was set to $20 \%$. A sensitivity analysis was carried out to test for $\mathrm{CV}=10 \%$ and $\mathrm{CV}=40 \%$.

Prior distributions.-Prior distributions were assigned to all other parameters for which Bayesian updating is expected after data integration (Table 3). Informative priors were set for parameters of the selectivity $S_{a}$, based on ICES (2009). Because the $\alpha_{i}$ 's and $\beta_{i}$ 's (i.e., instantaneous mortality rates, Eq. 4) are difficult to interpret, priors on the parameters of the hierarchical structure were set so that the resulting prior on the $K_{i}^{\prime}$ 's and $\psi_{i}$ 's (i.e., carrying capacity and maximal survival rate; Eq. 6) were weakly informative and slightly informative, respectively. As reviewed by Conn et al. (2010), the slope at the origin of stock-recruitment models $(\psi)$ is classically more difficult to estimate than the maximum recruitment $(K)$, and more attention to the prior choice on $\psi$ was required to avoid unrealistic inferences. The priors on the $K_{i}^{\prime}$ 's were weakly informative in the sense of Gelman (2009), i.e., it lets the data speak while being strong enough to exclude unrealistic values (the $80 \%$ percentile is $\sim 2 \mathrm{fish} / \mathrm{m}^{2}$, which is more than 100 times greater than the highest estimated density in nurseries of the Bay of Biscay; Le Pape et al. 2003). A more informative prior was set on the $\psi_{i}$ 's, with a prior mode consistent with estimates of survival between settlement in June and age-0 juveniles in summer (Dorel et al. 1989).

Because the $\psi_{i}$ 's and $K_{i}$ 's are key for the dynamics, and because the $\psi_{i}$ 's are a priori suspected to be difficult to estimate from the data alone (Conn et al. 2010), a sensitivity analysis to the prior on the $\alpha_{i}$ 's and $\beta_{i}$ 's (and thus on $\psi_{i}$ 's and $K_{i}$ 's) was carried out by testing more informative priors (Table 3). By contrast, inferences on parameters associated with the demographic model for ages 2 to 15 are a priori much more robust to the choice of priors. Indeed, this model component consists in a catch-at-age model for 14 age classes tracked over 27 years. Natural mortality is considered known, and catches and abundance indices are available for almost all years and ages. Inferences on associated parameters are logically strongly driven by the data.

Model comparison and model checking.-The four alternative hypotheses for the recruitment process, R1 to $\mathrm{R} 4$, were compared using deviance information criterion (DIC; Spiegelhalter et al. 2002) and synthetic criteria for predictive posterior checking (Gelman et al. 2004). Hypotheses R1 to R4 were compared under each scenario of larval drift and survival $D_{1}, D_{2}$, and $D_{3}$. DIC was computed with the deviance calculated at the level of each abundance indices $I_{0, y, i}, I_{1, y, i}, I_{a, y}$, and of catches $C_{a, y}$, but it is worth noting that the greatest part of the deviance is brought by the predictive performance for abundances of juveniles in each nursery sectors.

Posterior checking tests consist in checking the consistency between the fitted model (a posteriori) and the different sources of observations $I_{0, y, i}, I_{1, y, i}, I_{a, y}$ and 
$C_{a, y}$. For each source of observation $x$, the $\chi^{2}$ discrepancy was computed as a summary measure of the discrepancy over the whole time series $y=1, \ldots, n$

$$
\chi^{2}(x, \theta)=\sum_{y=1}^{y=n} \frac{\left(x_{y}-E\left(x_{y} \mid \theta\right)\right)^{2}}{\operatorname{Var}\left(x_{y} \mid \theta\right)}
$$

where $E\left(x_{y} \mid \theta\right)$ and $\operatorname{Var}\left(x_{y} \mid \theta\right)$ are the expected mean and variance in the noisy observation process given parameters $\theta$. For each set of parameters $\theta$ drawn in their joint posterior distribution, the realized discrepancies $\chi^{2}\left(x^{\text {obs }}\right.$, $\theta$ ) computed with the observed values of $x$ were compared to $\chi^{2}\left(x^{\text {pred }}, \theta\right)$ computed with the posterior predictive replicates of $x$. The Bayesian $P$ value is the probability that $\chi^{2}\left(x^{\text {pred }}, \theta\right)>\chi^{2}\left(x^{\text {obs }}, \theta\right)$, estimated over the posterior sample of $\theta$ (Gelman et al. 2004). The $P$ values were calculated for each source of observation to examine potential failure in different compartments of the model.

\section{Testing the performance of the estimation method through simulated data}

Objectives and scenarios.-The model was primarily designed to estimate the density-dependent and densityindependent mortality rates of settled larvae in nursery grounds (Eq. 4) and to unravel the contrast in the productivity between the different nurseries (Eq. 6). Three scenarios (S1-S3) were run to provide insights on the reliability of the estimation method in a context where observations are error prone and/or incomplete (Robert et al. 2010, Ono et al. 2012).

The baseline scenario S1 is designed to assess if the method provides reliable estimates in an ideal configuration where the time series of larval drift and survival rates is complete and known without error, and catches and abundance indices are available with no missing data. The detailed parameterization used for $\mathrm{S} 1$ is given in Appendix: Table A1).

Scenario S2 is modified from S1 to assess how the inferences deteriorate when missing data (in proportion similar to the real case study) arise in juvenile abundance indices in nursery grounds (Table 1) and in adult abundance indices.

Scenario S3 is modified from S2 to assess how sensitive are the estimates to an additional misspecification of the larval drift and survival rates, to mimic the application to the Eastern Channel case study where the larval drift and survival rates for many years were estimated from an informative Dirichlet prior distribution based on a 14-years times series (1991-2004).

Flow chart of the method.-

Step 1.-Each scenario first consisted in simulating time series of catches and abundance indices according to the operating model in Eqs. 1-13 with known parameters and randomness in process and observations (Appendix: Table A1). Simulations were tailored to fit the case study of the sole population in the EC. The population was simulated over 27 years with 15 age classes. We conducted 25 trials for each scenario, a number sufficient to quantify bias and uncertainty in estimates while limiting overall computational requirements. The 25 trials were not sufficient to precisely estimate bias and uncertainty, but results obtained with more trials (50 and 75 trials were tested on scenario S3) showed that the main conclusions about the capacity to unravel the contrast of productivity between nurseries were robust to the number of trials.

Step 2.- Simulated catches, abundance indices, larval drift and survival rates (including missing data in S2 and S3) were considered as data used to estimate the abundance trajectory and the underlying unknown parameters listed in Table 3.

Step 3.- The performance of the estimation method was evaluated with respect to how well the posterior distribution of parameters and state variables estimated the simulated values. Qualitative comparisons were supplemented by two quantitative criteria. First, the mean relative error (MRE) quantified the bias of the Bayesian estimates. For each unknown quantity $\theta$ and each simulation $s(s=1, \ldots, 25)$, the relative error was calculated as $\operatorname{RE}\left(\theta_{s}\right)=\left(\operatorname{med}\left(\theta \mid\right.\right.$ data $\left.\left._{s}\right)-\theta_{\text {true }}\right) / \theta_{\text {true }}$, with $\operatorname{med}\left(\theta \mid\right.$ data $\left._{s}\right)$ denoting the posterior median of $\theta$ given the data of the simulation $s \cdot \operatorname{MRE}(\theta)$ was calculated as the mean of $\operatorname{RE}\left(\theta_{s}\right)$ across the 25 simulation trials and was expressed as a percentage of error. Second, the mean coefficient of variation (MCV) measured the precision of the Bayesian estimation and was calculated as the mean of $\operatorname{CV}\left(\theta_{s}\right)$ across the 25 simulation trials, where

$$
\mathrm{CV}\left(\theta_{s}\right)=\sqrt{\operatorname{Var}\left(\theta \mid \mathrm{data}_{s}\right)} / E\left(\theta \mid \text { data }_{s}\right) .
$$

For unknown quantities defined on the time series, such as fish abundance, $\operatorname{RE}\left(\theta_{s}\right)$ and $\operatorname{CV}\left(\theta_{s}\right)$ were first averaged across the whole time series.

\section{Computational details}

All computations were performed within the $\mathrm{R}$ platform (R Development Core Team 2012). Bayesian posterior distributions were approximated via Monte Carlo-Markov chain methods through the open-source OpenBUGS software (Gelfand and Smith 1990, Lunn et al. 2009). Three MCMC-independent chains with dispersed initialization points were used. For each chain, the first 100000 iterations were discarded. After this "burn-in" period, inferences were derived from a sample of $3 \times 400000$ iterations. One out of 10 iterations was kept to reduce the MCMC sampling autocorrelation. All the modeling results have undergone the Gelman-Rubin test (Brooks and Gelman 1998) as implemented in the Coda package of $\mathrm{R}$ to assess convergence of MCMC chains ( $R$ ratio $<1.05$ for all variables).

Following the seminal idea of Meyer and Millar (1999) who proposed a parameterization of the biomass dynamic production model in terms of biomass relative to the carrying capacity to improve the convergence speed of the MCMC sampler, Eq. 1 was written with 


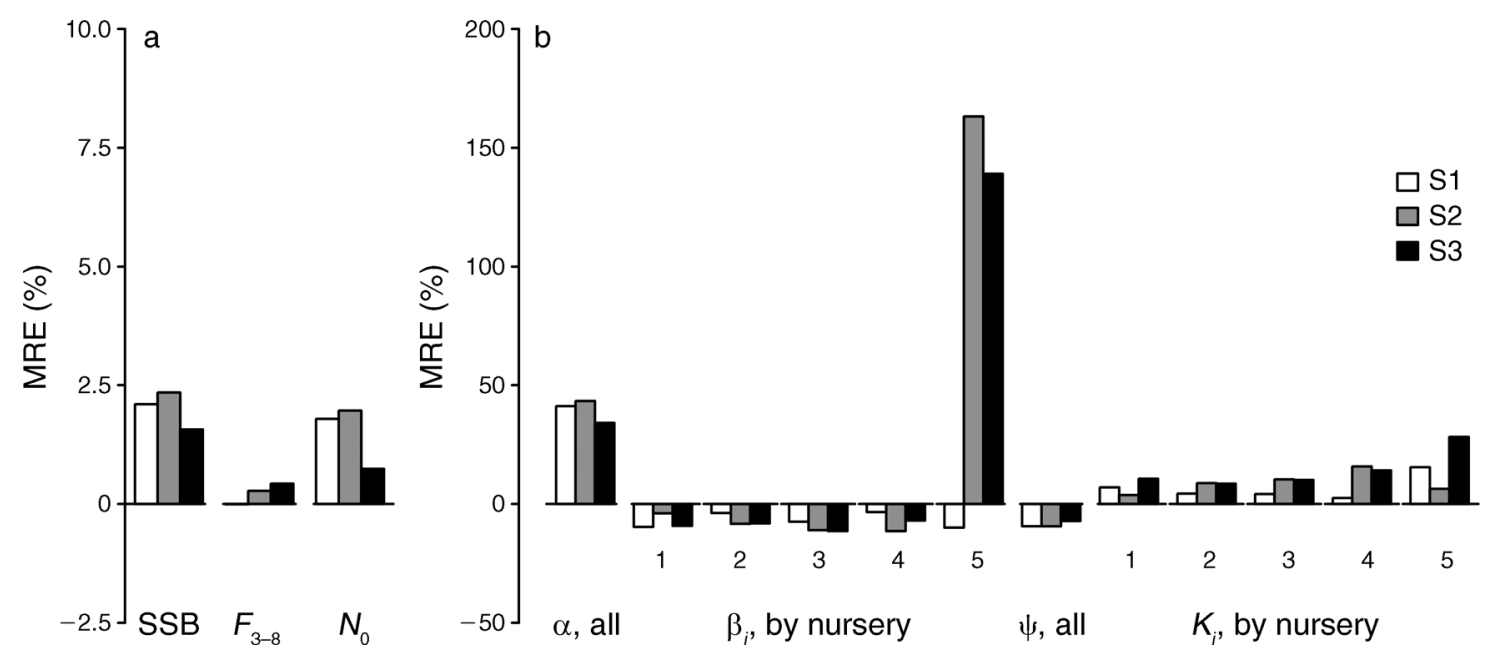

FIG. 3. Performance of the estimation method assessed by simulations (mean of the relative errors, MRE) for the key variables and parameters in the model under the three scenarios S1-S3 with the model recruitment configuration R3. S1 is the baseline scenario, where there are no missing data (Appendix: Table A1); S2 is S1 modified with missing data in juvenile and adult abundance indices; S3 is S2 modified with misspecification of the larval drift and survival rates. R3 stands for recruitment hypothesis 3 with the site-specific density-independent mortality rate $(\alpha)$ common to all nurseries and the site-specific densitydependent mortality rate $\left(\beta_{i}\right)$ being site-specific. (a) Aggregated measures of abundances: SSB (spawning-stock biomass), $N_{0}$, the total number of age- 0 juveniles in the five nursery sectors, and $F_{3-8}$, fishery mortality for the most heavily exploited age classes $3-8$. (b) Density-independent mortality rate, $\alpha$ (common to all nurseries); maximum survival rate, $\psi$ (common to all nurseries); densitydependent mortality rates, $\beta_{i}$ 's, for each nursery; and carrying capacities per unit of surface area, $K_{i}$ 's, for each nursery.

number at age relative to the recruitment of the cohort measured at age 1: $P_{a, y}=N_{a, y} / N_{1, y-a+1}$.

\section{RESUlTS}

\section{Insights from the simulation approach}

Abundance at age and fishery mortality.-The simulation tests indicated that our method provided good estimates of the time series of abundance and fishing mortality at different age classes (Appendix: Fig. A1). To estimate the overall model goodness of fit, the spawning stock biomass (SSB: total mass of all mature individuals in the population) was calculated as an aggregated measure of the abundance at age. The total number of age- 0 juveniles in the five nursery sectors $\left(N_{0}\right)$ was used as an indicator for the recruitment. The average fishing mortality for the most heavily exploited age classes 3 to $8\left(F_{3-8}\right)$ was used as an indicator of fishing mortality. The mean relative errors (MRE) were lower than $2.5 \%$ for the three indicators SSB, $N_{0}$, and $F_{3-8}$ (Fig. 3a), even for scenarios with missing data in abundance indices (S2) and with additional misspecification of the drift and survival probability (S3). SSB, $N_{0}$, and $F_{3-8}$ were estimated with low uncertainty. For instance, the mean coefficient of variation (MCV) for the scenario S3, having the weaker data, were found equal to $5.0 \%, 11.2 \%$, and $7.7 \%$ for SSB, $N_{0}$, and $F_{3-8}$, respectively. Posterior distributions of state variables associated to the adult population (ages 2-15) were not sensitive to change in prior distributions.

Recruitment dynamics in each nursery ground.-The density-independent mortality rate was generally esti- mated with moderate bias, with MRE between $30 \%$ and $40 \%$ for scenarios S1 to S3 (Fig. 3b). Estimates of the density-dependent mortality rate $\left(\beta_{i}{ }^{\prime}\right.$ s) were negatively biased around $-10 \%$, except for nursery five with MRE reaching $160 \%$ in the data-poor scenarios (S2 and S3; Fig. 3b). Uncertainty about the $\beta_{i}$ estimates was around $\mathrm{MCV}=34 \%$ for nurseries 1 to 4 and $40 \%$ to $100 \%$ for nursery five. Higher bias and uncertainties encountered in nursery five (Fig. 1, Veys) resulted from the absence of data for juvenile abundance indices (Table 1) in scenarios S2 and S3. As a consequence, the posterior distribution for $\beta_{5}$ is close to the posterior predictive derived from the hierarchical model (shrinkage effect; Appendix: Fig. A2), thus producing a larger bias than for other nurseries (Fig. 3b).

The method performed quite well in estimating the maximum survival rate between larvae and juveniles $(\psi)$ and the carrying capacities of each nursery ground $\left(K_{i}^{\prime}\right.$ 's). Interestingly, missing data in the juvenile abundance indices on nursery grounds and the misspecification in the larval drift and survival rates (S2-S3) slightly affected $\psi$, but seemed relatively inconsequential for the estimation performance of the site-specific carrying capacities. As suspected a priori, $\psi$ is more difficult to estimate than the $K_{i}^{\prime}$ 's and its posterior distribution could be influenced by the prior (leading to large MRE; Appendix: Fig. A2). By contrast, for all scenarios, the posterior distributions of the $K_{i}$ 's were generally well shaped (Appendix: Fig. A2), with MRE lower than 16\% (Fig. 3b) except for nursery five (28\% in S3). Comparison of $\mathrm{MCV}$ among the three scenarios revealed that 
TABLE 4. Model comparison (deviance information criteria, DIC) for application to the case-study data.

\begin{tabular}{ccccc}
\hline \hline & \multicolumn{4}{c}{$\begin{array}{c}\text { DIC for the four } \\
\text { model-configuration hypotheses }\end{array}$} \\
\cline { 2 - 5 } $\begin{array}{c}\text { Larval-drift } \\
\text { survival option }\end{array}$ & $\mathrm{R} 1$ & $\mathrm{R} 2$ & $\mathrm{R} 3$ & $\mathrm{R} 4$ \\
\hline$D_{1}$ & 9673 & 9668 & 9659 & 9659 \\
$D_{2}$ & 9663 & 9680 & 9662 & 9662 \\
$D_{3}$ & 9671 & 9665 & 9656 & 9657 \\
\hline
\end{tabular}

Notes: There are four competing recruitment hypotheses (R1-R4) about the between-nurseries variability of the densitydependent $(\beta)$ and density-independent $(\alpha)$ mortality rates: R1, $\alpha$ and $\beta$ are common to all nurseries; R2, the $\alpha$ 's are nurseryspecific, and the $\beta$ 's are common to all nurseries; R3, the $\beta$ 's are nursery-specific, and the $\alpha$ 's are common to all nurseries; and $\mathrm{R} 4$, the $\alpha$ 's and the $\beta$ 's are nursery-specific. Only poor information is available to site-specific parameters.

the precision of the estimation with regards to the $K_{i}^{\prime} \mathrm{s}$ slightly decreased when missing data and misspecification of the drift and survival rates were introduced (Appendix: Fig. A2). The largest loss in performance arose when introducing missing data in the juvenile abundance indices (S2): the average MCV increased from $22 \%$ to $36 \%$. As expected, the weakening of the estimation performance was particularly important for nursery five (Veys) for which no abundance indices were available (Table 1), with values of $\mathrm{MCV}=34 \%$ for $\mathrm{S} 1$ to $\mathrm{MCV}=76 \%$ for S3. Using the informative Dirichlet distribution for the drift and survival rates (S3) did not drastically impact the estimation performance as the average MCV of $K$ only increased from $34 \%$ to $36 \%$ between $\mathrm{S} 2$ and $\mathrm{S} 3$.

In summary, even in data-poor scenarios characterized by a significant proportion of missing data and by a partial misspecification of the drift survival rates (S2 and $\mathrm{S} 3$, with S3 being the closest to the case study), the method not only provided unbiased and precise estimates of the abundance at difference age classes and of the fishing mortality, but also accurately identified the age- 0 juveniles carrying capacities in the different nursery grounds. However, the method failed in providing reliable estimates when the proportion of missing data increases (e.g., nursery five).

\section{Application to the sole population in the Eastern Channel}

Model comparison and consistency.-The deviance information criterion (DIC; Spiegelhalter et al. 2002) provided support to the hypothesis that the densityindependent mortality rates $(\alpha)$ are common to all nurseries but that density-dependent ones $\left(\beta_{i}\right.$ 's) are sitespecific (i.e., model configuration for Hypothesis R3: the $\beta_{i}$ 's are nursery-specific and $\alpha$ is common to all nurseries). DIC were equal or only slightly different for R3 and R4 under all larval-drift scenarios (Table 4). Because the estimates of the $\alpha_{i}$ 's in R4 were very close to each other, the most parsimonious model configuration R3 was chosen.

Posterior checking under model configuration R3 did not reveal any strong inconsistency between the estimates and the data for the three larval drift and survival scenarios. No critical failures (identified by $P$ values near 0.05 or 0.95 ) were observed in any compartment of the model where observations were available (Table 5).

The variance around the average density-dependent mortality in each nursery ground was quite high (average posterior means of $\sigma_{R}^{2}=0.62$ with $[0.46$, 0.82] $90 \%$ Bayesian credibility interval). The residual variability did not reveal any particular departure from the hypotheses of constant variance across the five nursery grounds and of time independence of residuals.

Bayesian estimates of all key quantities (SSB, $F_{3-8}, N_{0}$, and all parameters) in the model appeared relatively robust to changes in the prior distribution of the expected mean and CV of the $\alpha_{i}$ 's and $\beta_{i}$ 's (Table 3). Hypothesizing smaller $(\mathrm{CV}=0.1)$ or larger $(\mathrm{CV}=0.4)$ observation errors in catches $\left(\sigma_{C}^{2}\right)$ was inconsequential for the posterior median of estimated parameters, while increasing the $\mathrm{CV}$ resulted in a slight increase in the uncertainty of the estimates. For instance, for SSB in the configuration $D_{1}-\mathrm{R} 3, \mathrm{MCV}$ was $4 \%, 6 \%$, and $8 \%$ for $\mathrm{CV}$ $=0.1,0.2$, and 0.4 , respectively. According to these preliminary analyses, only the results obtained under the model configuration $\mathrm{R} 3$ with the baseline value $\mathrm{CV}=0.2$ are reported in the following.

Abundance at age and fishing mortality.-Fig. 4 revealed that the Bayesian posterior estimates of the abundance at different age classes and of the fishery mortality were highly consistent with estimates from the stock assessment working groups (ICES 2009). The time series have similar trends, although the hierarchical Bayesian model (HBM) estimated a slightly higher SSB (posterior mean averaged over the time series = $+9 \%)$, balanced by a lower fishing mortality $(-7 \%)$. The total recruitment of age- 0 juveniles $\left(N_{0}\right)$ was also estimated at a higher level (average bias $=+13 \%$ ), but this difference largely results from the two last years $(+47 \%$ and $+208 \%$, respectively; Fig. 4$)$, which are often poorly estimated by catch-at-age models (Hilborn and Walters 1992). With three more years of

TABle 5. Posterior checking ( $P$ values) for application to the case-study data, under the model configuration R3.

\begin{tabular}{ccccc}
\hline \hline $\begin{array}{c}\text { Larval } \\
\text { drift }\end{array}$ & \multicolumn{4}{c}{$P$ value } \\
\cline { 2 - 5 } option & Survey age-0 & Survey age-1 & Catches & Survey CPUE $\dagger$ \\
\hline$D_{1}$ & 0.75 & 0.24 & 0.47 & 0.500 \\
$D_{2}$ & 0.75 & 0.22 & 0.47 & 0.499 \\
$D_{3}$ & 0.70 & 0.29 & 0.44 & 0.501
\end{tabular}

$\dagger$ CPUE is catch per unit effort. 
available data (1982-2011), results from the stock assessment in 2012 (ICES 2012) revealed a better consistency with the outputs of the Bayesian model (1982-2008), in particular for $N_{0}$. Uncertainties around estimates were low (Fig. 4) and increased in the last years of the time series as numbers-at-age are estimated from shorter cohort depletion (i.e., fewer age groups). The coefficient of variation of SSB, $F_{3-8}$, and $N_{0}$ were $6 \%, 9 \%$, and $13 \%$, respectively, when averaged over the entire time series, but $17 \%, 23 \%$, and $47 \%$, respectively, for the last year.

Recruitment dynamics in each nursery ground.-The total survival from eggs to settled larvae and the allocation to the five nursery sectors for the time series 1992-2004 derived from Rochette et al. (2012) are given at Fig. 5a and 5c. For the 1982-1991 and 2005-2008 periods the posterior distribution of the $D_{y, i}$ 's (from which total survival and allocation are deduced) depends upon the informative Dirichlet prior used in the different scenarios $D_{1}, D_{2}$, and $D_{3}$. In scenario $D_{2}$ (respectively, $D_{3}$ ) the informative Dirichlet is based on the first half (respectively, the second half) of the time series, and the posterior had the highest (respectively, the lowest) larval survival probability (Fig. 5b). The main difference in larval distribution among nurseries was for the Somme nursery, which was more supplied in scenario $D_{2}$ to the detriment of the U.K. West nursery and inversely for scenario $D_{3}$ (Fig. 5d). Uncertainty around $D_{y, i}$ 's was low compared to the contrasts between nurseries (Appendix: Fig. A3).

Inferences highlighted differences in the parameters of the density-dependent mortality process among the five nurseries, but their estimates were not sensitive to changes between $D_{1}, D_{2}$, and $D_{3}$ (Fig. 6; Appendix: Table A2). The density-independent mortality rate $\alpha$ (set common to all nurseries in model configuration R3) was estimated at a quite low value (posterior median at about 0.24 ) and with relatively low uncertainty (Fig. 6a; Appendix: Table A2 and Fig. A4). Differences in the $\beta_{i}$ 's suggested a higher density-dependent mortality for Somme, posterior medians being more than four times higher than in Rye Bay (Fig. 6b; Appendix: Table A2 and Fig. A4).

The maximum survival rate from settled larvae to age0 juveniles in autumn ( $\psi$, set common to all nurseries) was estimated at about 0.9 (Fig. 6c; Appendix: Table A2, Fig. A4). Consistently with the high contrast in the posterior estimates of $\beta_{i}$ 's among nurseries, carrying capacity estimates obtained under scenario $D_{1}$-R3 (Fig. 6d) showed that the Rye Bay nursery had the highest estimated carrying capacity $\left(K_{2}=198 \times 1000 \mathrm{fish} / \mathrm{km}^{2}\right)$, and Somme $\left(K_{3}=44 \times 1000 \mathrm{fish} / \mathrm{km}^{2}\right)$ the lowest (Fig. 6d; Appendix: Fig. A4).

As an additional interesting result, the model provided estimates of the time series of relative contribution of each nursery to the total recruitment of age- 0 juveniles (Fig. 7a). These different contributions resulted from the contrast in the standardized carrying capacities scaled
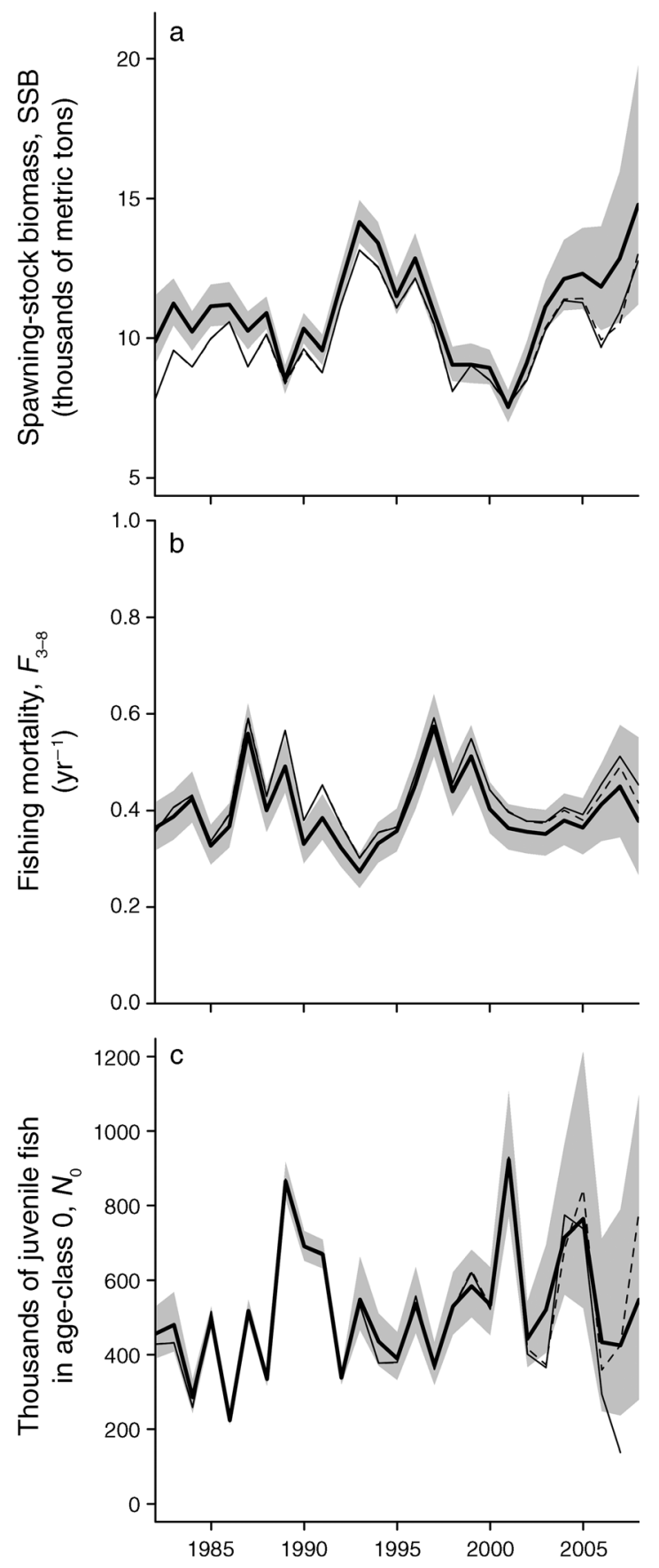

FIG. 4. Posterior estimates of the aggregated measures of abundance and fishing mortality obtained under the model configuration $D_{1}$-R3. (a) SSB, total mass of mature adults in the population; (b) $F_{3-8}$, average fishing mortality calculated over age classes 3-8; (c) $N_{0}$, total number of age- 0 juveniles summed over the five nursery grounds. Thin lines and thin dashed lines represent point estimates from the stock-assessment working group in 2009 (ICES 2009) and 2012 (ICES 2012), respectively. Bold lines are posterior means; the shaded area shows $90 \%$ Bayesian credibility intervals. 

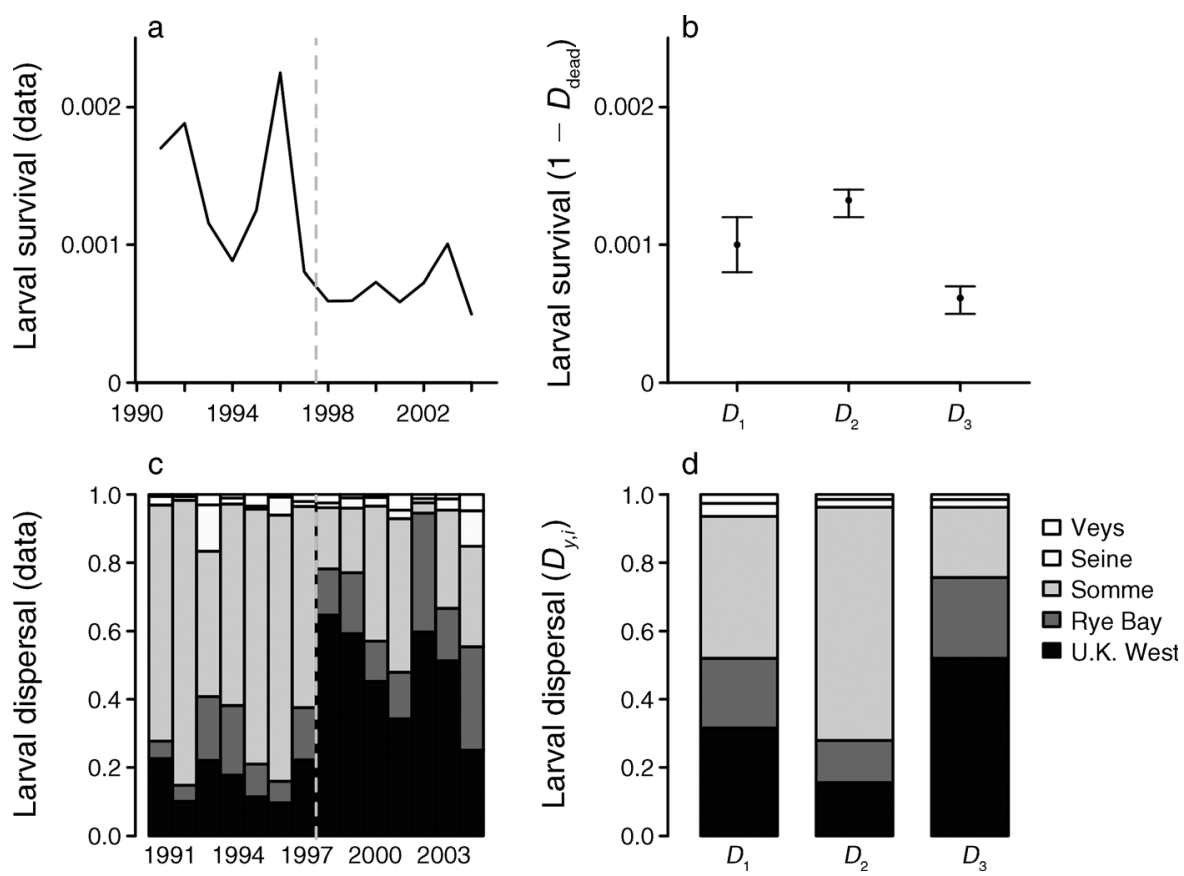

FIG. 5. Larval drift and survival ( $D_{y, i}$ 's) used in the model for the whole time series 1982-2008 under the three drift scenarios $D_{1}, D_{2}$, and $D_{3}$. (a, c) Time series 1991-2004 of inputs from Rochette et al. (2012) for (a) the total larval survival and (c) the larval allocation $\left(D_{y, i}\right.$ 's scaled to sum at 1$)$ in the five nursery sectors. We use the word "data" in the $y$-axis labels to indicate that this is a way to represent data before fitting the model [in contrast to panels (b) and (d), which are outputs of the model fitted in the present paper]. (b, d) Posterior estimates computed from an informative Dirichlet prior distribution based on the three drift scenarios $D_{1}$, $D_{2}$, and $D_{3}$ for (b) the total larval survival and (d) the allocation among nurseries. Error bars in panel (b) indicate inter-annual variability (minimum, mean, maximum) of the posterior medians.

by the surface area of each nursery (Table 1). The contributions of nurseries were quite stable among years, except in 1996 for which the model estimated a much higher contribution of the "Seine" nursery and in 1998-2000 and 2004, for which the Somme had the highest contribution (Fig. 7a). Fig. 7b showed that U.K. West had the highest production on average (average contribution $=30 \%$ of the total amount of age- 0 juveniles for a nursery area representing $29 \%$ of the Eastern Channel nurseries). The low carrying capacity of the Seine estuary combined with its limited surface area (21\% of the nurseries) led to a production of only $16 \%$ of the total recruitment of age- 0 juveniles, whereas the high surface area compensates for the low estimated capacity of the Somme estuary, which contributes on average $22 \%$ of the total age-0 recruitment.

Distribution of the survival rate during the life cycle.The model quantified the strength of cohort depletion and the distribution of the survival rate during the whole life cycle (Fig. 8). Most of the mortality occurred during the early life stages, particularly during the drift from eggs to settled larvae. The average survival of this critical phase was about $0.1 \%$ (1 settled larvae for 1000 eggs spawned). The average survival between settled larvae and age-1 was about $8.1 \%$, much higher than during the larval stage but lower than for adults (average annual survival from ages 2 to 10 was $\sim 70 \%$ ).

\section{DisCUSSION}

\section{A framework for integrated life-cycle modeling}

The present approach offers a substantial contribution toward integrated modeling of a fish life cycle in a spatial perspective. The nursery-dependent sole population in the Eastern Channel (Western Europe) was ideal for illustrating how the combination of different model components within an integrated hierarchical Bayesian model (HBM) provides estimates of hidden variables and parameters of biological significance and management interest, along with a fair appraisal of the associated uncertainty.

Insights from the simulation approach.-The simulation approach provided an assessment of the estimation performance of the HBM. The scenarios were designed to test for the extent to which gaps in the available information influence the performance in the estimation of key parameters. This issue was assessed (1) when a great proportion of missing data occurs in the abundance indices of juveniles in nurseries and (2) when only a weak representation of the larval-drift survival rates is provided by the larval drift model. This data configuration might be the rule rather than the exception in fish ecology or fisheries sciences. 

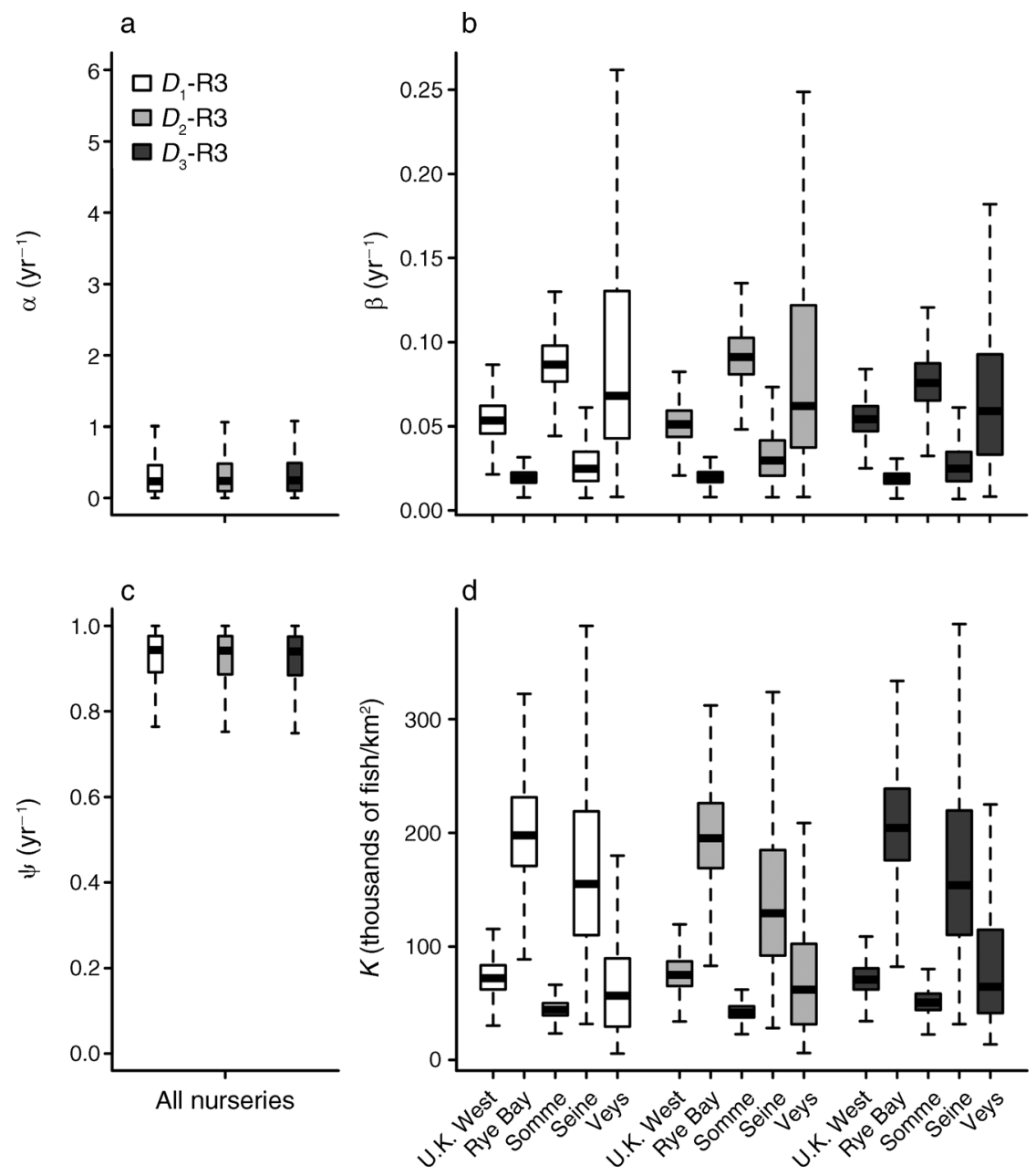

FIG. 6. Marginal posterior distributions for the parameters of the density-dependent mortality process in each nursery ground, under the model configuration $D_{1}$-R3: (a) $\alpha$ is the density-independent mortality rate, common to all nurseries; (b) $\beta_{i}$ 's are the density-dependent mortality rates; (c) $\psi$ is the maximum survival rate, common to all nurseries; (d) $K_{i}$ 's represent carrying capacities ( $\times 1000 \mathrm{fish} / \mathrm{km}^{2}$ of surface area). Boxplots represent medians (bar), $25 \%$ and $75 \%$ percentiles (boxes), and $2.5 \%$ and $97.5 \%$ percentiles (whiskers).

The methodology provided reliable, unbiased, and precise estimates of time series of abundance at age (and in particular the total recruitment at age-0) and of fishing mortality at age with low bias and uncertainty. Simulations showed that the approach also performed well in estimating the carrying capacities characterizing the productivity of each nursery ground. Interestingly, the misspecification in the larval drift and survival rates and the existence of missing data in the juvenile abundance indices in nursery sectors seemed relatively inconsequential for the performance of the estimation. However, results stressed the limited ability of the model to reliably estimate the site-specific density-dependent and density-independent parameters that shape the mortality between settled larvae and age- 0 juveniles. This limitation could have been anticipated a priori knowing the three sources of difficulty for statistical identification: (1) the lack of contrast in the simulated spawning biomass (Hilborn and Walters 1992), which remains quite steady during the simulated period (ICES 2009), (2) the large residual variability in the densitydependent survival (Houde 2008), and (3) missing data on larval supply and juvenile abundance indices.

Application to the sole population of the Eastern Channel.-Our model is the first attempt to merge a larval drift and survival model and a habitat suitability model with an age-structured population-dynamics model within a spatial perspective. Larval drift models are valuable tools to palliate the paucity of field observations for early life stages and to explore the influence of hydrodynamics on the dispersion and survival of early life stages (Miller 2007, Bonhommeau et al. 2009, Huret et al. 2010, Savina et al. 2010, Gallego et al. 2012). The individual-based model for larval drift 
a

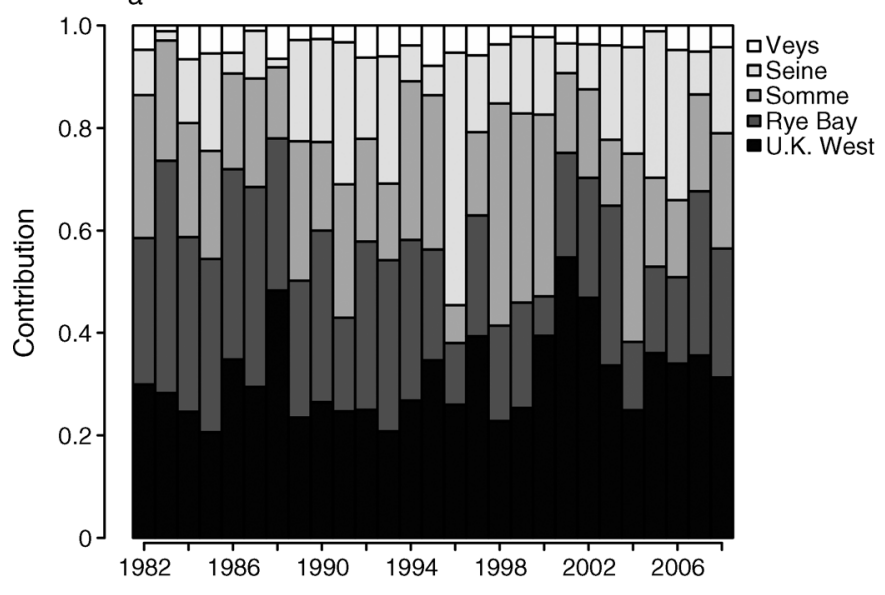

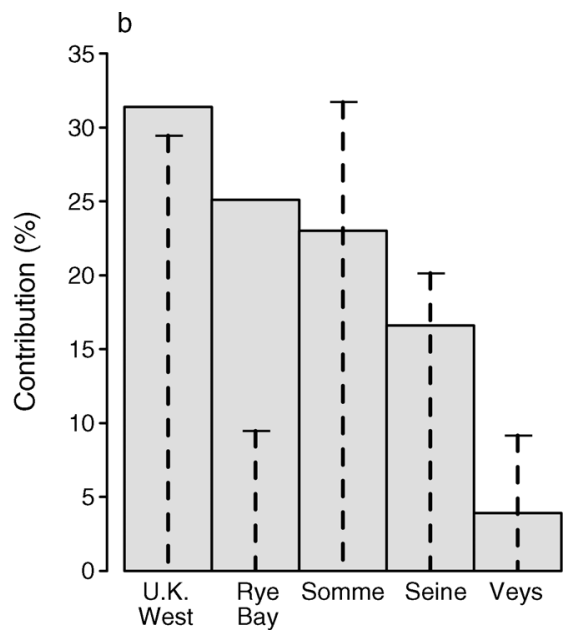

FIG. 7. Contribution of each nursery ground to the total recruitment of age- 0 juveniles in the Eastern Channel, estimated from posterior medians of $N_{0, y, i}$ 's under the model configuration $D_{1}-\mathrm{R} 3$. (a) Between-year variability of the proportional contribution of each nursery to the total recruitment of age- 0 juveniles in the population. (b) Gray bars are the average contribution (calculated across all years) of each nursery to the total recruitment. The vertical dashed lines indicate the surface area of each nursery as a percentage of the total surface area of nursery sectors, so that the difference between bars and dashed lines highlights the contrast in productivity.

of the common sole in the EC (Rochette et al. 2012) incorporates knowledge and hypotheses about the biology and ecology of early life stages (eggs and larvae) and the way they interact with variability in hydroclimatic conditions. This model provided yearly estimates of the mortality and dispersion of larvae from spawning grounds to coastal nurseries. Integrating the amounts of settled larvae and the spatial juvenile abundance indices together with the surface area of nurseries (derived from the habitat-suitability model of Rochette et al. [2010]) provided information about the productivity of each nursery sector and their contribution to the total amount of age- 0 juveniles. The catch-atage component of the model provided information to estimate the numbers-at-age from age- 0 juveniles to adults, which are used to estimate the spawning stock biomass and to complete the life cycle.

Results demonstrate that more can be learned from such an integrated approach of the life cycle that provided a quantification of the effects of multiple sources of pressure and mortality in different life stages (Stelzenmüller et al. 2011, van de Wolfshaar et al. 2011). First, the model provided posterior Bayesian distributions of the 1982-2008 time series of the spawning biomass (SSB), the ages 3-8 fishing mortality $\left(F_{3-8}\right)$, and the recruitment $\left(N_{0}\right)$, for which posterior medians were found to be similar to the estimations of the stock assessment working group (ICES 2009). In addition to classical stock-assessment procedures, our approach provides a fair appraisal of uncertainty on estimates of recruitment, abundance, and fishing mortalities. The model also presents some minor differences with the model used by ICES (2009). Catch data were considered as observed with lognormal errors with CV (coefficient of variation) $=20 \%$. The natural mortalities of age- 0 and age-1 juveniles are higher than the value $0.1 \mathrm{yr}^{-1}$ used by ICES (2009). Age-1 mortality $M_{1}$, fixed at 2.6 years $^{-1}$ was based on Dorel et al. (1989), which is more likely to reflect the high mortality rates observed for juveniles (Levin and Stunz 2005).

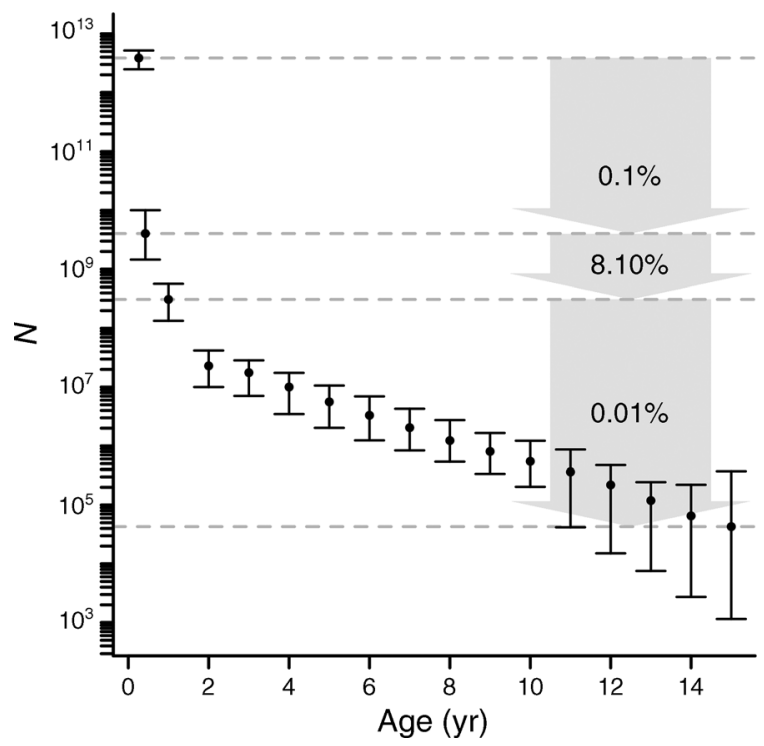

FIG. 8. Depletion of the total abundance during the life cycle of the common sole estimated under the model configuration $D_{1^{-}}$R3. $N$ is the total number of individuals in the Eastern Channel at the different ages of the life cycle; note that the $y$-axis is in log scale. The numbers in the pale-gray arrows indicate the average survival rates during the three main phases of the life cycle: from eggs to settled larvae; from settled larvae to age-1 juveniles; natural and fishing mortality during the harvested phase at sea. The solid black dots and vertical lines, respectively, indicate the mean and the between-years variability (minimum and maximum, respectively) of the posterior medians of estimated abundances between 1982 and 2008. 
Second, it was possible to assess the distribution of the survival rates during the whole life cycle. Results showed that most of the mortality occurs during the early life stages, a well-known pattern for marine fishes (Levin and Stunz 2005). The approach could be used to explore the consequences of the hydrodynamics on mortality and dispersion of larvae and the relative influence of SSB and hydrodynamics on the recruitment. For common soles in the EC, Rochette et al. (2012) pointed out that the amount of successful settled larvae was more sensitive to between-year variability of the hydrodynamics than to SSB fluctuations. Unfortunately, the larval drift survival was only available for 14 years (from 1991 to 2004) out of the 27 years of the time series. We used an informative Dirichlet prior distribution for the years where the larval drift survival was not available. This certainly contributed to the high level of the residual variance around the mortality of juveniles after settlement in nursery grounds. Even if the model confirmed that mortality is orders of magnitude lower after settlement than during the pelagic larval stage (van der Veer et al. 2000, Levin and Stunz 2005), the large proportion of missing data also impaired the model's ability to assess the relative contribution of the hydrodynamics and the variability of the post-settlement mortality in the total variability of the recruitment.

Third, the approach estimates the productivity of each nursery sector and their specific contribution to the recruitment and to the population renewal. This is a prerequisite for assessing how human-induced disturbances on those essential fish habitats impact the population dynamics and for sound assessment of spatial management measures (Fodrie et al. 2009, Planque et al. 2010, Stelzenmüller et al. 2011). The scenario with common density-independent and sitespecific density-dependent mortality rates revealed the best hypothesis to explain the data. The estimated contributions of each nursery ground to the total recruitment, that integrate both the carrying capacities per unit of surface area and the total surface area of each nursery sector, were consistent with previous findings about the respective contribution of these coastal and estuarine sectors to the abundance of age- 0 and age- 1 juveniles (Riou et al. 2001, Rochette et al. 2010).

\section{Directions for future improvements}

The approach provides a framework for structuring further research and data collection.

Results were conditioned by the outputs of the larval drift model (Rochette et al. 2012). Increasing the temporal extent of the larval drift model could greatly improve the understanding of site-specific densitydependent mortality and would allow assessments of the relative contribution of hydrodynamics and postsettlement mortality to the overall variability of the recruitment.

Assumptions were made in the juvenile mortality process that could also be improved. First, the density- dependent mortality from metamorphosis (settlement in June) to age-0 juvenile (survey in September) was assumed to follow a Beverton and Holt relationship. The underlying hypothesis is that the instantaneous mortality rate depends upon the density at each instant. Alternatively, mortality could depend upon the number of larvae at the time of metamorphosis only, leading to a Ricker-type relationship (Quinn and Deriso 1999). Second, a density-independent mortality was assumed between age- 0 and age- 1 juveniles, whereas the existence of a density-dependent mortality could be hypothesized (Dingsor et al. 2007). Although these different hypotheses could hardly be statistically tested because of the huge amount of residual variability, elaborating further on the mortality processes on young stages (Juanes 2007), by integrating more ecological knowledge and data about the critical settlement and post-settlement stages, could help improve the model and define future research directions.

The most exciting prospect is the potential to explore the role of connectivity between the different subpopulations associated with spawning and nursery grounds (Frisk et al. 2013). The present model assumed a total connectivity as all juveniles were part of a common SSB. While neutral genetic markers could not distinguish among subpopulations (Exadactylos et al. 2003), new and innovative approaches suggested a low level of connectivity between the different sub-populations (e.g., adaptative multi-markers; Cuveliers et al. 2012). Accordingly, Rochette et al. (2012) suggested that larval supply in each nursery might depend mostly on eggs spawned in its neighborhood. The low mobility of juveniles (Coggan and Dando 1988, Anonymous 1989) and adults (Kotthaus 1963, Anonymous 1965) confirmed by mark-recapture surveys (Burt and Millner 2008) suggests that migrations could be reduced to very small distances. Further research to explore different hypotheses on connectivity, and to assess the role of connectivity in the productivity and in the response of the whole population to spatial management measures (Carson et al. 2011, Stelzenmüller et al. 2011) are promising foci for future research.

In conclusion, the model presented here constitutes a valuable contribution to fish life-cycle modeling. The study demonstrates that more can be learned from integrated approaches combining simulations of oceanic circulation models for early life stages dispersion and survival with population dynamics modeling within a statistical Bayesian hierarchical modeling framework, used to integrate various sources of observations and to learn about hidden processes and unknown parameters. Our approach provides a framework that incorporates spatial variability in fish life-cycle parameters within the stock recruitment process. This framework will allow for the exploration of hypotheses concerning both the ecological factors underlying the contrasting productivity among nursery grounds and the role of connectivity in population dynamics. It should also be helpful when 
assessing impacts of multiple sources of stress (Blackwood et al. 2011, Layman et al. 2011, Stelzenmüller et al. 2011) and spatial management measures on fisheries.

\section{ACKNOWLEDGMENTS}

This research was funded by the French National Research Agency research project "Vulnérabilité, Milieux et Climat" (SoleBeMol-Pop), by the European Community's Seventh Framework Programme (FP7/2007-2013) under Grant Agreement number 266445 for the project Vectors of Change in Oceans and Seas Marine Life, Impact on Economic Sectors (VECTORS) and by the European Interreg 4a project "CHannel integrated Approach for marine Resource Management, Phase III" (Charm III). We thank the anonymous native English speakers and reviewers for their especially thorough work and insightful comments.

\section{Literature Cited}

Anonymous. 1965. Report of the working group on sole. Cooperative Research Report of the International Council for the Exploration of the Sea 5:1-126.

Anonymous. 1989. Report of the ad hoc Study Group on juvenile sole tagging. Ostende. ICES CM 1989/G21:1-34.

Beck, M. W., et al. 2001. The identification, conservation and management of estuarine and marine nurseries for fish and invertebrates. BioScience 51:633-641.

Blackwood, J. C., A. Hastings, and P. J. Mumby. 2011. A model-based approach to determine the long-term effects of multiple interacting stressors on coral reefs. Ecological Applications 21:2722-2733.

Bonhommeau, S., B. Blanke, A. M. Tréguier, N. Grima, E. Rivot, Y. Vermard, and O. Le Pape. 2009. How fast can the European eel larvae (Anguilla anguilla) cross the Atlantic ocean? Fisheries Oceanography 18(6):371-385.

Brooks, S. P. 2003. Bayesian computation: a statistical revolution. Philosophical Transactions of the Royal Society A 361:2681-2697.

Brooks, S. P., and A. Gelman. 1998. General methods for monitoring convergence of iterative simulations. Journal of Computational and Graphical Statistics 7(4):434-455.

Buckland, S. T., K. B. Newman, C. Fernandez, L. Thomas, and J. Harwood. 2007. Embedding population dynamics models in inference. Statistical Science 22:44-58.

Burt, G. J., and R. S. Millner. 2008. Movements of sole in the southern North Sea and eastern English Channel from tagging studies (1955-2004). Centre for Environment, Fisheries and Aquaculture Science, Lowestoft, UK.

Carson, H. S., G. S. Cook, P. C. López-Duarte, and L. A. Levin. 2011. Evaluating the importance of demographic connectivity in a marine metapopulation. Ecology 92:19721984.

Chambers, R. C., and E. A. Trippel. 1997. Early life history and recruitment in fish populations. Chapman and Hall, London, UK.

Coggan, R. A., and P. R. Dando. 1988. Movements of juvenile Dover sole, Solea solea (L.), in the Tamar Estuary, Southwestern England. Journal of Fish Biology 33:177-184.

Conn, P. B., E. H. Williams, and K. W. Shertzer. 2010. When can we reliably estimate the productivity of fish stocks? Canadian Journal of Fisheries and Aquatic Sciences. 67:511523.

Costanza, R., et al. 1997. The value of the world's ecosystem services and natural capital. Nature 387:253-260.

Cressie, N., C. A. Calder, J. S. Clark, J. M. Ver Hoeff, and C. K. Wikle. 2009. Accounting for uncertainty in ecological analysis: the strengths and limitations of hierarchical statistical modeling. Ecological Applications 19:553-570.

Cunningham, C. L., D. G. Reid, M. K. McAllister, G. P. Kirkwood, and C. D. Darby. 2007. A Bayesian state-space model for mixed-stock migrations, with application to
Northeast Atlantic mackerel Scomber scombrus. African Journal of Marine Science 29:347-367.

Cuveliers, E., M. Larmuseau, B. Hellemans, S. Verherstraeten, F. Volckaert, and G. Maes. 2012. Multi-marker estimate of genetic connectivity of sole (Solea solea) in the North-East Atlantic Ocean. Marine Biology 159:1239-1253.

Dingsor, G. E., L. Cianelli, K. S. Chan, G. Ottersen, and N. C. Stenset. 2007. Density dependence and density independence during the early life stages of four marine fish stocks. Ecology 88:625-634.

Dorel, D., Y. Desaunay, and J. Marchand. 1989. Prise en compte des migrations saisonnières des soles juvéniles pour l'estimation d'abondance des pré-recrues sur une nourricerie (Golfe de Gascogne, France). ICES CM/G30:1-7.

Drouineau, H., S. Mahevas, M. Bertignac, and D. Duplisea. 2010. A length-structured spatially explicit model for estimating hake growth and migration rates. ICES Journal of Marine Science 67:1697-1709.

Exadactylos, A., A. J. Geffen, P. Panagiotaki, and J. P. Thorpe. 2003. Population structure of Dover sole Solea solea: RAPD and allozyme data indicate divergence in European stocks. Marine Ecology Progress Series 246:253-264.

Fässler, S. M. M., M. R. Payne, T. Brunel, and M. DickeyCollas. 2011. Does larval mortality influence population dynamics? An analysis of North Sea herring (Clupea harengus) time series. Fisheries Oceanography 20:530-543.

Fernandez, C., S. Cervino, N. Pérez., and E. Jardim. 2010. Stock assessment and projections incorporating discard estimates in some years: an application to the hake stock in ICES Divisions VIIIc and IXa. ICES Journal of Marine Science 67:1185-1197.

Fodrie, J., L. Levin, and A. Lucas. 2009. Use of population fitness to evaluate the nursery function of juvenile habitats. Marine Ecology Progress Series 385:39-49.

Frisk, M. G., A. Jordaan, and T. J. Miller. 2013. Moving beyond the current paradigm in marine population connectivity: are adults the missing link? Fish and Fisheries. http:// dx.doi.org/10.1111/faf.12014

Gallego, A., E. North, and E. D. Houde. 2012. Understanding and quantifying mortality in pelagic, early life stages of marine organisms - old challenges and new perspectives. Journal of Marine Systems 93:1-3.

Gelfand, A. E., and A. F. M. Smith. 1990. Sampling-based approaches to calculating marginal densities. Journal of the American Statistical Association 85:398-409.

Gelman, A. 2009. Bayes, Jeffreys, prior distributions and the philosophy of statistics. Statistical Science 24(2):176-178.

Gelman, A., J. B. Carlin, H. Stern, and D. B. Rubin. 2004. Bayesian data analysis. Second edition. Texts in Statistical Science, Chapman and Hall, New York, New York, USA.

Gibson, R. N. 2005. Flatfishes: biology and exploitation. Blackwell Publishers, Oxford, UK.

Grüss, A., D. M. Kaplan, S. Guenette, C. M. Roberts, and L. W. Botsford. 2011. Consequences of adult and juvenile movement for marine protected areas. Biological Conservation 144:602-702.

Hilborn, R., and C. J. Walters. 1992. Quantitative fisheries stock assessment: choice, dynamics, and uncertainty. Chapman and Hall, New York, New York, USA.

Hinrichsen, H.-H., M. Dickey-Collas, M. Huret, M. A. Peck, and F. B. Vikebo. 2011. Evaluating the suitability of coupled biophysical models for fishery management. ICES Journal of Marine Science 68:1478-1487.

Houde, E. D. 2008. Emerging from Hjort's shadow. Journal of Northwest Atlantic Fisheries Society 41:53-70.

Huret, M., P. Petitgas, and M. Woillez. 2010. Dispersal kernels and their drivers captured with a hydrodynamic model and spatial indices: a case study on anchovy (Engraulis encrasicolus) early life stages in the Bay of Biscay. Progress in Oceonography 87:6-17. 
ICES. 2009. Report of the Working Group on the Assessment of Demersal Stocks in the North Sea and Skagerrak Combined Spring and Autumn (WGNSSK), 6 - 12 May 2009, ICES Headquarters, Copenhagen, Denmark.

ICES. 2012. Report of the Working Group on the Assessment of Demersal Stocks in the North Sea and Skagerrak Combined Spring and Autumn (WGNSSK), 27 April - 3 May 2012. ICES Headquarters, Copenhagen, Denmark.

Iles, T. C., and J. H. Beverton. 2000. The concentration hypothesis: the statistical evidence. ICES Journal of Marine Science 57:216-227.

Juanes, F. 2007. Role of habitat in mediating mortality during the post-settlement transition phase of temperate marine fishes. Journal of Fish Biology 70:661-677.

Kotthaus, A. 1963. Tagging experiments with the North Sea sole (Solea solea) in 1959 and 1960. Pages 123-129 in Special Publication number 4 of the International Comission for the Nowthwest Atlantic Fisheries. Headquarters of the Commission, Dartmouth, Nova Scotia, Canada.

Kuparinen, A., S. Mäntyniemi, J. A. Hutchings, and S. Kuikka. 2012. Increasing biological realism of fisheries stock assessment: towards hierarchical Bayesian methods. Environmental Reviews 20(2):135-151.

Laurent, A. G. 1963. The log-normal distribution and the translation method: description and estimation problems. Journal of American Statistical Association 58:231-235.

Layman, C. A., J. E. Allgeier, A. D. Rosemond, C. P. Dahlgren, and L. A. Yeager. 2011. Marine fisheries declines viewed upside down: human impacts on consumer-driven nutrient recycling. Ecological Applications 21:343-349.

Le Pape, O., F. Chauvet, S. Mahevas, P. Lazure, D. Guerault, and Y. Desaunay. 2003. Quantitative description of habitat suitability for the juvenile common sole (Solea solea, L.) in the Bay of Biscay (France) and the contribution of different habitats to the adult population. Journal of Sea Research 50:139-149.

Levin, P. S., and G. W. Stunz. 2005. Habitat triage for exploited fishes: can we identify essential fish habitat? Estuarine Coastal and Shelf Science 64:70-78.

Lewy, P., and A. Nielsen. 2003. Modelling stochastic fish stock dynamics using Markov Chain Monte Carlo. ICES Journal of Marine Science 60:743-752.

Lunn, D., D. Spiegelhalter, A. Thomas, and N. Best. 2009. The BUGS project: evolution, critique and future directions. Statistics in Medicine 28:3049-3067.

Maunder, M. N., and R. B. Deriso. 2011. A state-space multistage life cycle model to evaluate population impacts in the presence of density dependence: illustrated with application to delta smelt (Hyposmesus transpacificus). Canadian Journal of Fisheries and Aquatic Sciences 68:1285-1306.

May, R. C. 1974. Larval mortality in marine fishes and the critical period concept. Pages 3-19 in J. H. S. Blaxter, editor. The early life history of fishes. Springer-Verlag, Berlin, Germany.

McAllister, M. K., S. L. Hill, D. J. Agnew, G. P. Kirkwood, and J. R. Beddington. 2004. A Bayesian hierarchical formulation of the De Lury stock assessment model for abundance estimation of Falkland Islands' squid (Loligo gahi). Canadian Journal of Fisheries and Aquatic Sciences 61:1048-1059.

Mesnil, B., and J. G. Shepherd. 1990. A Hybrid age- and length-structured model for assessing regulatory measures in multiple-species, multiple-fleet fisheries. ICES Journal of Marine Science 47:115-132.

Meyer, R., and R. B. Millar. 1999. BUGS in Bayesian stock assessments. Canadian Journal of Fisheries and Aquatic Sciences 56:1078-1086.

Millar, R. B., and R. Meyer. 2000. Bayesian state-space modeling of age-structured data: fitting a model is just the beginning. Canadian Journal of Fisheries and Aquatic Sciences 57:43-50.
Miller, T. 2007. Contribution of individual-based coupled physical-biological models to understanding recruitment in marine fish populations. Marine Ecology Progress Series 347:127-138.

Minto, C., R. A. Myers, and W. Blanchard. 2008. Survival variability and population density in fish populations. Nature 452:344-348.

Newman, K. B., C. Fernández, L. Thomas, and S. T. Buckland. 2009. Monte Carlo inference for state-space models of wild animal populations. Biometrics 65:572-583.

Ono, K., A. E. Punt, and E. Rivot. 2012. Model performance analysis for Bayesian biomass dynamics models using bias, precision and reliability metrics. Fisheries Research 125-126:173-183.

Parent, E., and E. Rivot. 2012. Introduction to hierarchical Bayesian modeling for ecological data. Applied Environmental Statistics. CRC Press, Boca Raton, Florida, USA.

Pelletier, D., and S. Mahevas. 2005. Spatially explicit fisheries simulation models for policy evaluation. Fish and Fisheries 6(4):307-349.

Petitgas, P., A. D. Rijnsdorp, M. Dickey-Collas, G. H. Engelhard, M. A. Peck, J. K. Pinnegar, K. Drinkwater, M. Huret, and R. D. M. Nash. 2013. Impacts of climate change on the complex life cycles of fish. Fisheries Oceanography 22(2):121-139.

Planque, B., J. M. Fromentin, P. Cury, K. F. Drinkwater, S. Jennings, R. I. Perry, and S. Kifani. 2010. How does fishing alter marine populations and ecosystems sensitivity to climate? Journal of Marine System 79:403-417.

Planque, B., C. Loots, P. Petitgas, U. Lindstrom, and S. Vaz. 2011. Understanding what controls the spatial distribution of fish populations using a multi-model approach. Fisheries Oceanography 20:1-17.

Quinn, T. J., and R. B. Deriso. 1999. Quantitative fish dynamics. Oxford University Press, New York, New York, USA.

R Development Core Team. 2012. R: a language and environment for statistical computing. R Foundation for Statistical Computing, Vienna, Austria.

Riou, P., O. Le Pape, and S. I. Rogers. 2001. Relative contributions of different sole and plaice nurseries to the adult population in the Eastern Channel: application of a combined method using generalized linear models and a geographic information system. Aquatic Living Resources 14:125-135.

Rivot, E., and E. Prévost. 2002. Hierarchical Bayesian analysis of capture-mark-recapture data. Canadian Journal of Fisheries and Aquatic Sciences 59:1768-1784.

Rivot, E., E. Prévost, A. Cuzol, J.-L. Baglinière, and E. Parent. 2008. Hierarchical Bayesian modelling with habitat and time covariates for estimating riverine fish population size by successive removal method. Canadian Journal of Fisheries and Aquatic Sciences 65:117-133.

Rivot, E., E. Prevost, E. Parent, and J. L. Baglinière. 2004. A Bayesian state-space modelling framework for fitting a salmon stage-structured population dynamic model to multiple time series of field data. Ecological Modelling 179:463-485.

Robert, M., A. Faraj, M. K. McAllister, and E. Rivot. 2010 Bayesian state-space modelling of the De Lury depletion model: strengths and limitations of the method, and application to the Moroccan octopus fishery. ICES Journal of Marine Science 67:1272-1290.

Rochette, S., M. Huret, E. Rivot, and O. Le Pape. 2012. Coupling hydrodynamic and individual-based models to simulate long-term larval supply to coastal nursery areas. Fisheries Oceanography 21:229-242.

Rochette, S., E. Rivot, J. Morin, P. Riou, and O. Le Pape. 2010. Effect of nursery habitat degradation on flatfish population: application to Solea solea in the Eastern Channel (Western Europe). Journal of Sea Research 64:34-44. 
Ruiz, J., R. González-Quirós, L. Prieto, and G. Navarro. 2009 A Bayesian model for anchovy (Engraulis encrasicolus): the combined forcing of man and environment. Fisheries Oceanography 18:62-76.

Savina, M., G. Lacroix, and K. Ruddick. 2010. Modelling transport of common sole larvae in the Southern North Sea: influence of hydrodynamics and larval vertical movements. Journal of Marine Systems 81:86-98.

Simmonds, E. J., E. Portilla, D. Skagen, D. Beare, and D. G. Reid. 2010. Investigating agreement between different data sources using Bayesian state-space models: an application to estimating NE Atlantic mackerel catch and stock abundance. ICES Journal of Marine Science 67:1138-1153.

Spiegelhalter, D. J., N. G. Best, B. P. Carlin, and A. Van der Linde. 2002. Bayesian measures of model complexity and fit. Journal of the Royal Statistical Society: Series B (Statistical Methodology) 64:583-639.

Stelzenmüller, V., T. Fock, H. O. Schulze, and J. Berkenhagen. 2011. Integrating modelling tools to support risk-based decision-making in marine spatial management. Marine Ecology Progress Series 441:197-212.

Swain, D. P., I. D. Jonsen, J. E. Simon, and R. Myers. 2009. Assessing threats to species at risk using stage-structured state-space models: mortality trends in skate populations. Ecological Applications 19:1347-1364.
Thomas, L., S. T. Buckland, K. B. Newman, and J. Harwood. 2005. A unified framework for modelling wildlife population dynamics. Australian and New Zealand Journal of Statistics 47:19-34.

van der Land, M. A. 1991. Distribution of flatfish eggs in the 1989 egg surveys in the Southeastern North Sea, and mortality of plaice and sole eggs. Netherlands Journal of Sea Research 27:277-286.

van der Veer, H. W., A. J. Geffen, and J. I. Witte. 2000. Exceptionally strong year classes in plaice Pleuronectes platessa: Are they generated during the pelagic stage only, or also in the juvenile stage? Marine Ecology Progress Series 199:255-262.

van de Wolfshaar, K. E., R. HilleRisLambers, and A. Gårdmark. 2011. Effect of habitat productivity and exploitation on populations with complex life cycles. Marine Ecology Progress Series 438:175-184

White, C., and C. Costello. 2011. Matching spatial property rights fisheries with scales of fish dispersal. Ecological Applications 21:350-362.

Ying, Y., Y. Chen, L. Lin, T. Gao, and T. Quinn. 2011. Risks of ignoring fish population spatial structure in fisheries management. Canadian Journal of Fisheries and Aquatic Sciences 68:2101-2120.

\section{Supplemental Material}

\section{Appendix}

Detailed tables of parameters used for simulations and tables and figures of estimations of specific posterior distributions issued from simulations and from data (Ecological Archives A023-085-A1).

\section{Supplement}

Commented BUGS code that refers to scenario R3 with common $\alpha_{i}$ 's and hierarchical $\beta_{i}$ 's (Ecological Archives A023-085-S1). 